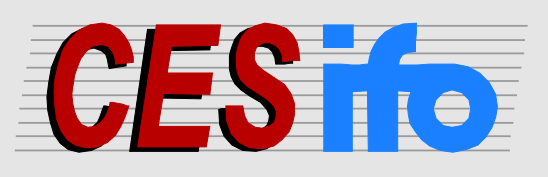

\title{
Working
}

Papers

www.cesifo.org/wp

\section{Simultaneous Supplies of Dirty and Green Fuels with Capacity Constraint: Is there a Green Paradox?}

\author{
Marc Gronwald \\ Ngo Van Long \\ Luise Röpke
}

\begin{abstract}
CESIFO WORKING PAPER NO. 4360
CATEGORY 9: RESOURCE AND ENVIRONMENT ECONOMICS

August 2013
\end{abstract}

An electronic version of the paper may be downloaded

- from the SSRN website:

- from the RePEc website:

- from the CESifo website:

wWw.SSRN.com

www.RePEc.org

www.CESifo-group.org/wp

\section{CESifo}




\title{
Simultaneous Supplies of Dirty and Green Fuels with Capacity Constraint: Is there a Green Paradox?
}

\begin{abstract}
This paper contributes to the green paradox literature by using a resource extraction framework with heterogeneous energy sources. A key feature of the model is a capacity constrained green backstop resource, which implies the simultaneous use of the expensive backstop resource and the cheaper exhaustible resources, over some interval of time. Two dirty exhaustible resources are considered, reflecting cost structure and carbon content heterogeneities of energy sources. The policies under consideration are taxation of the dirty resources and the promotion of the green resource via subsidies or capacity-increasing measures. The key findings, compared to a baseline scenario without policy intervention, are that (1) expanding the capacity of the green sector can decrease social welfare, (2) both green energy promotion measures lead to increases in short-term emissions, and (3) none of the analyzed policy measures leads to a decrease in the aggregate duration of the extraction of the exhaustible resources.
\end{abstract}

JEL-Code: Q380, Q540, H230.

Keywords: capacity constraints, green paradox, climate change.

Marc Gronwald
Ifo Institute-Leibniz-Institute for Economic Research
at the University of Munich
Poschingerstraße 5
Germany - 81679 Munich
gronwald@ifo.de

NgoVan Long

Department of Economics

McGill University

Canada - Montreal H3A 2T7

ngo.long@mcgill.ca
Luise Röpke

Ifo Institute - Leibniz-Institute for

Economic Research

at the University of Munich

Poschingerstraße 5

Germany - 81679 Munich

roepke@ifo.de

July 2013 


\section{Introduction}

Scientific evaluation of the severity of the threat of climate change has increased the priority accorded to policies aimed at mitigating carbon emissions. The most prominent developments toward decarbonization of the global economy are in the area of green energy production: the replacement of coal-fired power plants by wind turbines and solar power stations, as well as the use of biofuels as substitutes for fossil fuels in the transport sector. In many parts of the world, various policy measures have been introduced in order to push these developments: among these are the EU-wide energy policy goals, subsidies such as feed-intariffs at national levels, and various regional incentives for the production of green energy. The inevitable consequence of this decarbonization process is a complete reconstruction of the entire energy sector.

This reconstruction is not a simple matter. Investment projects in the development of green energies are not only large scaled and complex ventures, but also of a very long term nature; and there are still various challenges that need to be met. For example, in the field of fuel development, increasing the use of biofuels is beset by many problems of food security and sustainability, as well as technological constraints. In short, the decarbonization process is limited in many respects and green energy cannot be used to the extent that many would wish. In consequence, conventional fuels continue to be predominant. Strangely, however, even though, in addition to the above-mentioned problems, biofuels are not competitive, we observe that they are used simultaneously with conventional fuel types. These two features - implementation difficulties and simultaneous use of resources with different costs - are also apparent in the context of renewable-source electricity. Transforming existing electricity transmission networks is extremely expensive, as is the provision of sufficient storage facilities for renewable-source electricity. But again, even though green electricity is considerably more expensive than conventional sources - the costs for producing wind and solar power being much greater than the costs of producing conventional thermal electricity - both types of electricity are being generated and used simultaneously.

Although these two facts - green energy is capacity-constrained and it is used simultaneously with conventional energy - are obvious, they are not adequately considered in the evaluation of climate policies. The aim of this paper is to remedy this by using an extended Hotelling resource extraction model with a capacity-constrained backstop technology in order to analyze the effects of green policies. The effects of different policy measures on emission paths as well as their social consequences are studied both analytically and numerically. Our 
model is formulated to correspond to the concrete oil market example, and our numerical analysis involves oil market features allowing for an investigation of the use of conventional oil, unconventional oils, and biofuels. In consequence, this model is able to capture many empirically relevant problems of the transformation of the energy sector.

Our paper is related to two streams of literature. The first of these is the "green paradox" literature, which deals with the effects of green policies on the extraction decisions of carbon resource owners. Sinn's (2008) paper on this so-called green paradox is highly important as it sparked enormous research efforts (see, e.g., Gerlagh, 2011, Hoel, 2011, Grafton et al., 2012, van der Ploeg and Withagen, 2012a, 2012b). In this paper, Sinn considers a scenario in which owners of carbon resources are confronted with green policies that are expected to become stricter over time. He shows that this can provide exhaustible resource owners with an incentive to accelerate rather than postpone the extraction of the carbon resource. Thus, a well-intended but poorly designed climate policy can have detrimental effects for the climate. For example, Hoel (2008) shows that if clean energy can be supplied at constant and positive marginal costs and without a capacity constraint, a policy of committing to subsidize the production of the clean energy will induce market participants to expect a lower price for fossil fuels in the future, leading to more extraction of fossil fuels sooner, resulting in the fossil fuel stock being exhausted sooner and hence producing a green paradox outcome. Thus, in the Hoel (2008) model, subsidizing clean energy increases carbon emissions (assuming that the subsidy is not accompanied by other policy measures). In line with Sinn's argument, using a model with country heterogeneity, Hoel's (2011) found that lowering the costs of producing a substitute for carbon resources or imposing carbon taxes can have undesirable consequences since, under specified conditions, those policy measures can speed up the use of the carbon resource producing a green paradox result. The green paradox literature is vast, but, to our knowledge, there has been no explicit consideration of the possibility of green paradox outcomes in a framework with capacity-constrained green resources, which is clearly more realistic. This is somewhat surprising as there is a literature on the order of resource extraction showing that this kind of constraints can have substantial effects on the optimal order of exploitations of deposits. ${ }^{1}$

Indeed, it is this very order of extraction literature that provides the second motivation for this paper. This stream of literature has its origin in Herfindahl (1967). However, the original finding that resources with different constant marginal extraction costs are extracted in strict order from low to high-cost, the so-called Herfindahl rule, has been repeatedly called

\footnotetext{
${ }^{1}$ Chakravorty, Tidball and Moreaux (2008) considered the optimal order of exploitations if non-renewable deposits have different carbon contents. They imposed overall capacity constraints on extractions, but did not address the issue of the green paradox.
} 
into question. For example, Kemp and Long (1980) and Amigues et al. (1998) both show, in a general equilibrium setting, that when the inexhaustible substitute can be supplied only in constrained amounts, the extraction order deviates from the standard Herfindahl path. The contribution to the extraction order literature that is most relevant to this paper is Holland (2003), which finds similar results using a partial equilibrium model. Holland argues, in line with the resource literature, that resource owners base their extraction decision not only on marginal extraction costs, but also on the scarcity rent of the resources. The crucial feature of the model, however, is that some extraction capacities are limited, which has important implications for the optimal order of resource extraction. In such a situation, energy from the inexhaustible resource may be used in parallel to and even strictly before some exhaustible resource stocks that have lower marginal costs. The resulting extraction patterns are similar to the ones we actually observe.

Based on a reinterpretation of Holland's (2003) model, we evaluate whether results obtained by Sinn $(2008)$ and Hoel $(2008,2011)$ also hold in our model with two exhaustible resources and one capacity-constrained green backstop. We model the backstop technology in line with Dasgupta and Heal (1974), as a "perfectly durable commodity, which provides a flow of services at constant rate."We analyze different scenarios, for example, different taxation of the exhaustible resources or a marginal expansion of the green capacity, for their green paradox effects. We find conditions under which a green paradox outcome will arise.

The analysis employs the notions of a "weak green paradox" and a "strong green paradox" introduced by Gerlagh (2011) as well as an "overall green paradox" effect. The first refers to a short-term increase of anthropogenic emissions due to a policy measure, the overall green paradox effect refers to an overall increase, and the strong green paradox to an overall negative welfare effect (increased social damages) compared to the baseline scenario.

Our analytical results are complemented by a numerical welfare analysis, in which we formulate an explicit social damage function, analyze specific accumulation behavior of the anthropogenic carbon in the atmosphere, and investigate the situation where various deposits have different carbon content. Moreover, for the purpose of illustration, we introduce the example of an oil market with exhaustible resources being conventional and unconventional oil and a capacity-constrained green backstop technology. Based on different specifications of a green paradox, we numerically evaluate the overall welfare effect by looking at the social consequences of the various policy scenarios compared to a base case without policy intervention. While the strong green paradox is the most important effect for the analysis, the other green 
paradox effects are also worth analyzing since they provide additional insight into market behavior that will have an impact on the short- and medium-term effects of a policy measure.

The remainder of the paper is organized as follows. In the next section, we derive a model of substitute production under a capacity constraint based on Holland (2003). Sections 3 and 4 present a policy analysis with an implicit determination of the endogenous variables and the comparative static analysis of the different policy scenarios and a welfare analysis, respectively. Section 5 discusses the policy relevance of this paper. Section 6 offers some concluding remarks.

\section{A model of substitute production under capacity constraint}

Assume that there are two deposits of fossil fuels, $S_{1}$ and $S_{2}$. The constant per unit extraction costs for these deposits are $c_{1}$ and $c_{2}$, respectively. There are no capacity constraints on the amount of extraction at any given point of time $t$, i.e., no upper bounds on $q_{1}(t)$ and $q_{2}(t)$. The cumulative extraction constraints are

$$
\int_{0}^{\infty} q_{i}(t) d t \leq S_{i} \text { for } i=1,2 .
$$

There is a clean energy that is a perfect substitute for the fossil fuels. Let $q_{3}(t)$ be the amount of clean energy produced at time $t$. Assume there is a capacity constraint on clean energy production: $q_{3}(t) \leq \bar{q}_{3}$. This means that at each point of time, the amount of green energy that can be produced is exogenously determined by the capacity constraint. Let $c_{3}$ be constant unit costs of production of the clean energy.

Let $Q(t)=q_{1}(t)+q_{2}(t)+q_{3}(t)$ denote the aggregate supply of energy from the three resources at time $t$, where some of these $q_{i}(t)$ may be zero. The utility of consuming $Q(t)$ is $U[Q(t)]$, where $U(\cdot)$ is a strictly concave and increasing function and $U^{\prime}(0)$ can be finite or infinite. Moreover, assume $c_{1}<c_{2}<c_{3}<U^{\prime}(0)$.

The total welfare is

$$
\int_{0}^{\infty} e^{-r t}\left[U[Q(t)]-\sum_{i=1}^{3} c_{i} q_{i}(t)-C[V(t)]\right] d t
$$

where $V(t)$ is the volume of $\mathrm{CO}_{2}$ in the atmosphere at time $t$, and $C(V)$ is the damage cost function with $C^{\prime}(V)>0$ and $C^{\prime \prime}(V) \geq 0$. 
We assume that $\mathrm{CO}_{2}$ emissions are proportional to the consumption of fossil fuels $q_{1}(t)$ and $q_{2}(t)$ :

$$
\varepsilon_{1}(t)=\eta_{1} q_{1}(t) \text { and } \varepsilon_{2}(t)=\eta_{2} q_{2}(t)
$$

where $\eta_{1}$ and $\eta_{2}$ are positive coefficients.

Our first task is to characterize the equilibrium in the perfect competition situation. Consumer' demand is represented by the condition $p=U^{\prime}(Q) \equiv \phi(Q)$, where $\phi(Q)$ is strictly decreasing. Inverting this function, we obtain the demand function

$$
Q=D(p), D^{\prime}(p)<0
$$

The resource owners follow a Hotelling-like extraction path, maximizing the value of the resource stocks such that the resource rent increases at the rate of interest. The extraction order of the exhaustible resource stocks is based on the Herfindahl rule: low-cost resource stock is strictly exhausted before the high-cost resource stock is extracted. Since the renewable resource owners do not have to optimize intertemporally, their supply behavior is different from that of the exhaustible resource owners. In the next subsection, we assume that the parameters of the models satisfy two conditions that ensure that the high-cost renewable energy will be produced simultaneously with extraction of the lowest cost deposit, and well before the lower cost stock $S_{2}$ enters into production. These conditions were first identified by Holland (2003). We impose these conditions so that the model reflects the real-world energy market situation described in the introduction to this paper. Based on those conditions, the resulting extraction phases and prices can be outlined.

\subsection{Extraction capacity and cost reversal}

Based on Holland (2003), two conditions are imposed to ensure that both a binding capacity constraint of the renewable energy, as well as the cost reversal phenomenon, can be illustrated in the model. By "cost reversal", we mean that the higher cost renewable resource is produced well before the intermediate cost exhaustible resource begins to be extracted. In specifying the capacity constraint, we describe the real-world situation where even though in theory we have enough renewable energy resources, only a limited amount of that energy is practically available due to technological and economic constraints. To sharpen the consequences of this situation, we focus in the following analysis on the case where the capacity constraint is binding when green energy is produced. Then, at price $p=c_{3}$, the market demand $D\left(c_{3}\right)$ foe energy exceeds the capacity output of the clean energy sector $\bar{q}_{3}$. This is stated in the 
following condition.

\section{Condition 1: $D\left(c_{3}\right)>\bar{q}_{3}$}

So, when $p(t)$ reaches $c_{3}$, the market demand must be met from both the clean energy sector and fossil fuel extraction.

Since the demand curve is downward sloping, Condition 1 implies that there exists a value $\bar{p}>c_{3}$ such that $D(\bar{p})=\bar{q}_{3}$. Therefore, for all $p$ in the range $\left[c_{3}, \bar{p}\right]$, the clean resource will always be produced at maximum capacity. The equilibrium price of energy can never exceed $\bar{p}$, even when $U^{\prime}(0)=\infty .^{2}$

The second condition is that the size of the high-cost exhaustible resource must be small enough such that the cost reversal of resource use described in the introduction can be illustrated with the present model. An analytical derivation of this condition can be found in Appendix A.

$$
\text { Condition 2: } S_{2}<S_{2}^{\max } \equiv \int_{0}^{x} D\left[c_{2}+\left(c_{3}-c_{2}\right) e^{r \tau}\right] d \tau-\frac{\bar{q}_{3}}{r} \ln \left[\frac{\bar{p}-c_{2}}{c_{3}-c_{2}}\right]
$$

where we define $x$ by

$$
x=\frac{1}{r} \ln \left[\frac{\bar{p}-c_{2}}{c_{3}-c_{2}}\right]
$$

From condition 2, we can show that if the size of deposit 2 is smaller than the threshold value $S_{2}^{\max }$, the equilibrium time path of extraction is continuous and production of green energy starts strictly before the extraction of the high-cost resource deposit $S_{2}$ begins (Holland 2003). ${ }^{3}$

\footnotetext{
${ }^{2}$ We will not consider the alternative case where the capacity constraint is nonbinding, i.e., $D\left(c_{3}\right)<\bar{q}_{3}$. In this case, at price $p=c_{3}$, market demand $D\left(c_{3}\right)$ is lower than capacity output $\bar{q}_{3}$. In this situation, the capacity constraint $q_{3} \leq \bar{q}_{3}$ is never binding and green energy production could be anything up to $D\left(c_{3}\right)$ (completely replacing the exhaustible resources). The energy price will rise along the Hotelling path until it reaches $c_{3}$, afterwards it remains at $p=c_{3}$ forever. Before the price reaches $c_{3}$, the only supply is from the exhaustible resource deposits since the efficient level of supply of the renewable is $q_{3}(t)=0$ when $p(t)<c_{3}$. In the razor edge case defined by $D\left(c_{3}\right)=\bar{q}_{3}$, Holland (2003) finds that, when the price just reaches $c_{3}$, the supply of renewable energy can be anything between zero and $\bar{q}_{3}$ and afterwards the price will remain at $c_{3}$ forever.

${ }^{3}$ While Condition 1 can be understood as a necessary condition, Condition 2 can be understood as a sufficient condition for cost reversal. Moreover, the analyzed situations, based on the stated conditions, must be viewed as extreme cases. The model could also be designed to lead to a smooth increase in the production of green energy until the constraint is reached (which would be in accordance with actual observations in, for example, Germany). For simplicity and to sharpen our results, we believe it is useful to retain the strong assumptions. Determining a "dynamic capacity increase" would allow differentiating between constraints on existing production and natural capacity restrictions. Modeling such a differentiation would allow us to show a smooth and increasing use of green energy while maintaining the constrained situation.
} 


\subsection{Four phases of resource utilisation and the price path}

Based on Conditions 1 and 2, the equilibrium path of the energy price is continuous and the resource use pattern can be described as follows (see also Holland, 2003, Figure 1).

Phase 1: Energy is supplied only by extraction from the low-cost deposit. This phase begins at time 0 and ends at an endogenously determined time $t_{3}>0$, such that the equilibrium price at time $t_{3}$ is equal to $c_{3}$. During this phase, the net price of the low-cost resource, $p(t)-c_{1}$, rises at a rate equal to the interest rate $r$.

Phase 2: Energy is simultaneously supplied by both extraction from the low-cost resource deposit $S_{1}$ and the (more costly) renewable energy running at its capacity level $\bar{q}_{3}$. This phase begins at time $t_{3}$ and ends at an endogenously determined time $T>t_{3}$. (In a limiting case, when Condition 2 holds with equality, we have $T=t_{3}$, meaning that Phase 2 degenerates to a single point.) The low-cost resource stock $S_{1}$ is entirely exhausted at time $T$. During this phase, the net price of the low-cost exhaustible resource, $p(t)-c_{1}$, also rises at a rate equal to the interest rate $r$.

Phase 3: Energy is simultaneously supplied by both extraction from the high-cost resource deposit $S_{2}$ and the (more costly) renewable energy running at its capacity level $\bar{q}_{3}$. This phase begins at time $T$ and ends at an endogenously determined time $\bar{T}$. At time $\bar{T}$, the stock $S_{2}$ is completely exhausted. During this phase the net price of the higher cost exhaustible resource, $p(t)-c_{2}$, rises at a rate equal to the interest rate $r$. At time $\bar{T}$, the energy price reaches $\bar{p}$ (where $\bar{p}$ is defined by the equation $D(\bar{p})=\bar{q}_{3}$ ).

Phase 4: The only source of energy is the green energy, available at the capacity level $\bar{q}_{3}$. The price is constant at $\bar{p}$. This phase begins at time $\bar{T}$ and continues for ever (because the time horizon is infinite).

Note that from time $t_{3}$ on, where $p\left(t_{3}\right)=c_{3}$, the clean energy sector will supply $\bar{q}_{3}$ without any intertemporal considerations, and due to the assumption stated in Condition 1, there will not be enough energy to meet the demand $D\left(c_{3}\right)$. The shortfall, or residual demand, is met by extraction from the lowest-cost deposit available such that at $t_{3}$,

$$
\bar{q}_{3}+q_{1}\left(t_{3}\right)=D\left(c_{3}\right) .
$$

Or, in other words, only the residual demand must be met by the exhaustible resource, indicating that the existence of a constrained renewable resource alleviates the scarcity problem of the exhaustible resources. ${ }^{4}$

\footnotetext{
${ }^{4}$ The reason deposit 2 is not extracted during the time interval $\left[t_{3}, T\right)$ is that any attempt to move
} 
Holland (2003) does not provide explicit equations that specify how the length of various phases depends on parameters such as $c_{1}, c_{2}, c_{3}, \bar{q}_{3}, S_{1}$ and $S_{2}$. In what follows, we derive such equations, which help us obtain interesting comparative static results.

\section{Policy scenario analysis}

In the subsections below, we develop explicit expressions for determining the length of the various phases. Based on these, we investigate the conditions under which energy policy measures to alleviate climate change damages due to exhaustible resource use are effective when a capacity-contrained renewable energy source is available. Is it still true that a subsidy on renewable energy will harm the environment (Section 3.2.1)? Does a marginal expansion of the capacity help or hurt the mitigation efforts (Section 3.2.2)? Moreover, what are the effects of different ways of taxing exhaustible resource use (Sections 3.2.3 and 3.2.4)?

\subsection{Implicit determination of the endogenous variables}

Define $y$ to be the length of Phase 3, i.e., the phase during which deposit 2 is extracted. Then $y \equiv \bar{T}-T$. Since total demand must equal total supply during $[T, \bar{T})$ and deposit 2 must be exhausted during this interval, we can solve for $y$ from the equation

$$
\int_{T}^{\bar{T}} D[p(t)] d t=S_{2}+(\bar{T}-T) \bar{q}_{3}
$$

Since $q_{2}(t)>0$ over the time interval $[T, \bar{T})$, the Hotelling rule applied to deposit 2 must hold with equality such that

$$
p(t)=c_{2}+\left(\bar{p}-c_{2}\right) e^{r(t-T-y)}
$$

with $t-\bar{T}=t-T-(\bar{T}-T){ }^{5}$ Inserting this into equation (1), together with $\tau=t-T$, and noting that $\bar{p}$ and $\bar{q}_{3}$ are related through the equation $\bar{q}_{3}=D(\bar{p})$, then $y$ is the solution of the following equation:

$$
0=F\left(S_{2}, \bar{p}, c_{2}\right)=\int_{0}^{y} D\left[c_{2}+\left(\bar{p}-c_{2}\right) e^{r(\tau-y)}\right] d \tau-y D(\bar{p})-S_{2}
$$

extraction from $S_{2}$ to that interval to replace the high-cost clean energy would require curtailing consumption during the phase $[T, \bar{T})$, which implies costs in terms of foregoing consumption smoothing.

${ }^{5}$ Analogous to the Appendix, $p(t)$ can be derived from the condition $\left(p(t)-c_{2}\right) e^{-r t}=\left(p(T)-c_{2}\right) e^{-r T}=$ $\left(p(\bar{T})-c_{2}\right) e^{-r \bar{T}}$. 
where $S_{2}<S_{2}^{\max }(\infty)$ as stated in Condition 2 .

Remark: It is clear that an increase in $S_{2}$ will increase $y$. The proof is as follows. Keeping $\bar{p}$ and $c_{2}$ constant, and differentiating the previous equation totally, we obtain

$$
\left\{\left[D\left(c_{2}\right)-D(\bar{p})\right]-r\left(\bar{p}-c_{2}\right) \int_{0}^{y}\left(e^{r(\tau-y)}\right) D^{\prime}\left[c_{2}+\left(\bar{p}-c_{2}\right) e^{r(\tau-y)}\right] d \tau\right\} d y=d S_{2} .
$$

Thus

$$
\frac{\partial y}{\partial S_{2}}>0
$$

Having solved for $y$, we can determine the price at time $T$, when the high-cost deposit begins to extracted, as

$$
p(T)=c_{2}+\left(\bar{p}-c_{2}\right) e^{-r y} \equiv p_{2}
$$

Next, we can determine the length of the time interval $\left[t_{3}, T\right)$ over which energy demand is met by both extraction from the lowest cost deposit and via production of renewable energy at capacity level. We denote this length by $z \equiv T-t_{3}$. Then, since $p\left(t_{3}\right)=c_{3}$ by definition, the Hotelling rule gives

$$
z=\frac{1}{r} \ln \left[\frac{p(T)-c_{1}}{c_{3}-c_{1}}\right]
$$

Substituting for $p(T)$, we obtain

$$
0=G\left(y, c_{1}, c_{2}, c_{3}, \bar{p}\right)=\left(c_{3}-c_{1}\right) e^{r z}-\left(c_{2}-c_{1}\right)-\left(\bar{p}-c_{2}\right) e^{-r y}
$$

It is easy to see that

$$
\frac{\partial z}{\partial y}<0
$$

From equations (4) and (7), we conclude that an increase in $S_{2}$ will reduce $z$. Specifically, as $S_{2}$ approaches $S_{2}^{\max }$, z approaches zero. Moreover, analogously to the determination of $y$ in equation (1), since, over the period $[0, T]$ the total demand for energy must equal total supply that comes from deposit 1 and from renewable energy produced at capacity after time $t_{3}$, we know that $T$ must satisfy the equation

$$
\int_{0}^{T} D[p(t)] d t=S_{1}+\left[T-t_{3}\right] \bar{q}_{3}
$$

where, since deposit 1 is extracted over the interval $[0, T)$, the Hotelling rule applies to this 
deposit over that period:

$$
p(t)=c_{1}+\left(c_{2}-c_{1}\right) e^{r(t-T)}+\left(\bar{p}-c_{2}\right) e^{r(t-T-y)} .
$$

Finally, from inserting equation (9) into (8), we obtain the following equation which determines $T$ :

$$
0=H\left(y, z, T, c_{1}, c_{2}, \bar{p}\right)=\int_{0}^{T} D\left[c_{1}+\left(c_{2}+\left(\bar{p}-c_{2}\right) e^{-r y}-c_{1}\right) e^{r(t-T)}\right] d t-S_{1}-z D(\bar{p})
$$

\subsection{Comparative statics}

In this section, different policy scenarios aimed at reducing anthropogenic carbon emissions are analyzed with regard to their effects on supply-side extraction and production behavior. We also differentiate between a weak green paradox (as introduced by Gerlagh, 2011) and an overall green paradox. A weak green paradox is said to arise when an apparently green-oriented policy results in a short-run increase in emissions. In our analysis, a weak green paradox can be identified as a decrease of $p(0)$, which indicates higher initial resource extraction and/or a decrease in $T$. An overall green paradox occurs when the overall extraction duration of both resources (which is represented by $\bar{T}$ in our paper) decreases due to the policy measure. Moreover, later in the welfare analysis, we introduce the concept of a strong green paradox (borrowed from Gerlagh 2011), which occurs when the policy is environmentally harmful over the long run (e.g., when the present value of the stream of future damages increases due to greater accumulated emissions at all times up to time of exhaustion).

To assess the possibility of a green paradox, we apply the implicit function theorem to the system of equations (3), (6), and (10) to determine the response of the endogenous variables $(y, z, T)$ as well as of price behavior, to changes in the exogenous parameters $c_{1}, c_{2}, c_{3}$, and $\bar{p}$. The changes in the exogenous parameters are assumed to result from four different policy measures (two taxes on the exhaustible resources, subsidization of the renewable resource, and an exogenous increase in capacity) intended to slow down carbon extraction.

\subsubsection{Effect of a subsidy for renewable energy}

In the first part of our comparative static analysis, we investigate how subsidizing clean energy affects the extraction speed of the exhaustible resources. From the literature, we know that a subsidy can have detrimental effects on the environment if the clean energy is available at a constant cost without capacity constraint (see, e.g., Hoel, 2008). But does a 
green paradox also arise in the presence of a capacity-constrained green energy source or can this source alleviate pressure on exhaustible resource use? Examples of such subsidy systems include the renewable energy feed-in tariffs in Germany and Sweden and the exemption of biofuels from taxation. In the following, subsidization of green energy is modeled as a decrease of the constant marginal production cost, $c_{3}$. The effect of a change in $c_{3}$ on the endogenous variables $(y, z, T)$ can be computed from the following matrix equation

$$
\left[\begin{array}{ccc}
F_{y} & F_{z} & F_{T} \\
G_{y} & G_{z} & G_{T} \\
H_{y} & H_{z} & H_{T}
\end{array}\right]\left[\begin{array}{c}
d y \\
d z \\
d T
\end{array}\right]=\left[\begin{array}{c}
-F_{c_{3}} \\
-G_{c_{3}} \\
-H_{c_{3}}
\end{array}\right] d c_{3}
$$

where

$$
\begin{gathered}
F_{y}=-r\left(\bar{p}-c_{2}\right) \int_{0}^{y} D^{\prime}[p(\tau)] e^{r(\tau-y)} d \tau>0 \\
G_{y}=r\left(\bar{p}-c_{2}\right) e^{-r y}>0 \\
G_{z}=r\left(c_{3}-c_{1}\right) e^{r z}>0 \\
G_{c_{3}}=e^{r z}>0 \\
H_{y}=\int_{0}^{T} D^{\prime}[p(t)]\left[-r\left(\bar{p}-c_{2}\right) e^{-r y} e^{r(t-T)}\right] d t>0 \\
H_{T}=-D(\bar{p})<0 \\
D[p(T)]+\int_{0}^{T} D^{\prime}[p(t)]\left[-r e^{r(t-T)}\right]\left(c_{2}+\left(\bar{p}-c_{2}\right) e^{-r y}-c_{1}\right) d t>0 \\
F_{z}, F_{T}, F_{c_{3}}, G_{T}, H_{c_{3}}=0 .
\end{gathered}
$$

Let $J$ denote the determinant of the $3 \times 3$ matrix on the left-hand side of equation (11). Calculation shows that

$$
J=F_{y} G_{z} H_{T}>0
$$

Then, using Cramer's rule, we obtain the effect of an increase in $c_{3}$ on the variables $y, z$, and $T$ :

$$
\begin{gathered}
\frac{d y}{d c_{3}}=0 \\
\frac{d z}{d c_{3}}=\frac{-e^{r z}}{J}\left[F_{y} H_{T}\right]<0 \\
\frac{d T}{d c_{3}}=\frac{e^{r z}}{J}\left[F_{y} H_{z}\right]<0
\end{gathered}
$$

Thus, we see from equations (12)-(14) that an increase in the clean energy producer's unit 
cost, $c_{3}$, has no effect on the length of time over which deposit 2 is extracted $\left(d y / d c_{3}=0\right)$, but will shorten the life of the low-cost deposit $1\left(d T / d c_{3}<0\right)$ and will also shorten the interval of time over which both $q_{1}$ and $q_{3}$ are positive $\left(d z / d c_{3}<0\right)$. The initial price $p(0)$ will be higher, as can be derived from equation (9):

$$
\frac{d p(0)}{d c_{3}}=-r\left(c_{2}+\left(\bar{p}-c_{2}\right) e^{-r y}-c_{1}\right) e^{-r T} \frac{d T}{d c_{3}}>0
$$

Since $\bar{p}$ and $y$ are not affected by the increase in $c_{3}$, we can deduce that the price at which the high cost deposits begins to be extracted will be unaffected, see equation (5):

$$
\frac{d p_{2}}{d c_{3}}=0
$$

The effect of an increase in $c_{3}$ on $t_{3}$ (i.e., on the time interval over which all energy is supplied from deposit 1 alone) can also be computed. Since $t_{3}+z=T$,

$$
\frac{d t_{3}}{d c_{3}}=\frac{d T}{d c_{3}}-\frac{d z}{d c_{3}}=\frac{e^{r z} F_{y}}{J}\left[H_{z}+H_{T}\right]>0 .
$$

The analytical results are summarized in Proposition 1.

Proposition 1: Subsidizing the clean energy product results in a lower initial price of energy. This leads to a faster extraction of the lowest-cost exhaustible resource during the initial phase $\left[0, t_{3}\right)$. However, this phase itself is shortened ( $t_{3}$ is brought closer to time 0 ), and thus clean energy production will begin earlier. This effect allows deposit 1 to be extracted over a longer period. Therefore, in total and contrary to Hoel's (2008) model where subsidization clean energy ( a fall in $c_{3}$ ) results in earlier exhaustion of the exhaustible resource, subsidizing clean energy lengthens the life of the aggregate resource stock (i.e., an increase in $y+T$ in our model). Thus, there is a weak green paradox effect, but no overall green paradox effect.

This first result can be understood as follows (see also the illustrated price path in Section 4.2): subsidization of the renewable energy is equivalent to a decrease in $c_{3}$. From $d y / d c_{3}=0$ (equation (12)), we know that subsidizing the renewable backstop has no effect on how long it will take to exhaust $S_{2}$. Let $T^{*}$ denote the time of exhaustion of $S_{1}$ when the renewable technology is subsidized. Let the equilibrium price path that results from the subsidy be denoted by $\widetilde{p}(t)$. From the invariance of $y$, it follows that $\widetilde{p}\left(T^{*}\right)=p(T)$. This in turn ensures that the aggregated supply of energy over the length of time $y$ equals the demand.

Moreover, $d T / d c_{3}<0$ (equation (14)) implies that subsidization of the renewable resource 
increases the time span of extraction of $S_{1}$ by $\left(T^{*}-T\right)$. This means that resource stock $S_{1}$ is available for longer and the price level $p(T)=\widetilde{p}\left(T^{*}\right)$ is reached later.

Additionally, an intuitive explanation of the effect of a green-energy subsidy on the extraction $q_{1}$ at the production start date of the renewable energy and, therefore, on $z$ is as follows. If the price path were not affected, subsidizing the backstop would lead to earlier production of the renewable energy, implying that, given the unchanged time path of price, the supply of energy is greater than demand. Since this situation would be a disequilibrium, the price path must change. In consequence, $p(0)$ (see Section 4.2 , Figure $1, p_{0}$ ) declines to $p^{*}(0)$ (Section 4.2, Figure 1, $p_{0}^{*}$ ), as seen in equation (15). This decrease moderates the decline in $t_{3}$, restoring the balance between supply and demand; still, the analytical results show that $t_{3}^{*}<t_{3}$ (equation (16)).

These considerations show that two opposed effects work on $T^{*}$ and $z$. (1) Due to the decrease of $c_{3}, t_{3}$ decreases (equation (16)), which increases $T$ since, as $q_{3}$ is available earlier, it can alleviate the demand for $q_{1}$ sooner. This effect tends to increase $z$. (2) To equalize demand and supply at $t_{3}, p(0)$ decreases, as explained previously (see equation (15)). This second effect works in a direction opposite to the first effect and tends to postpone $t_{3}$ and also to shorten z. Moreover, due to a lower initial price level, the demand for energy increases and is satisfied by an increase in $q_{1}$ in period $\left[0, t_{3}\right)$. Which of the two effects dominates depends on their relative strength, which has been analyzed analytically. From $d T / d c_{3}<0$ and $d z / d c_{3}<0$ (equations (14) and (13)), we find that the first effect is stronger than the second. This means that the exhaustible-resource-saving effect (of the subsidy on renewable energy) on $S_{1}$ dominates the demand-increasing effect of the price decrease (the effect of $d T / d c_{3}+d y / d c_{3}$ is unambiguous).

Therefore, when there is a subsidization of the renewable backstop under capacity constraint, there is no overall green paradox effect in the long run, but there is a weak green paradox effect over the time interval $\left[0, t_{3}\right)$.

\subsubsection{Effect of an increase in capacity}

We now investigate the effect of an increase in capacity $\bar{q}_{3}$, which could occur due to a technological breakthrough such as, for example, the repowering of wind mills or a change from first-generation to second-generation biofuels. Moreover, an increase in capacity is equivalent to a decrease in the capacity-induced choke price $(\bar{p})$.

\section{The general case}

The effect of a change in $\bar{q}_{3}$ on the endogenous variables $(y, z, T)$, which is identical to a change in $\bar{p}$ since $D(\bar{p})=\bar{q}_{3}$, can be computed, analogously to the previous section, as 
follows:

$$
\left[\begin{array}{lll}
F_{y} & F_{z} & F_{T} \\
G_{y} & G_{z} & G_{T} \\
H_{y} & H_{z} & H_{T}
\end{array}\right]\left[\begin{array}{c}
d y \\
d z \\
d T
\end{array}\right]=\left[\begin{array}{c}
-F_{\bar{p}} \\
-G_{\bar{p}} \\
-H_{\bar{p}}
\end{array}\right] d \bar{p}
$$

where

$$
\begin{gathered}
F_{\bar{p}}=-y D^{\prime}(\bar{p})+\int_{0}^{y} D^{\prime}[p(\tau)] e^{r(\tau-y)} d \tau \gtrless 0 \\
G_{\bar{p}}=-e^{-r y}<0 \\
H_{\bar{p}}=-z D^{\prime}(\bar{p})+\int_{0}^{T} D^{\prime}[p(t)] e^{r(t-T-y)} d t \gtrless 0 .
\end{gathered}
$$

The comparative static results are ambiguous:

$$
\begin{gathered}
\frac{d y}{d \bar{p}}=\frac{-F_{\bar{p}}}{J}\left[G_{z} H_{T}\right] \text { has the sign of }-F_{\bar{p}} \\
\frac{d z}{d \bar{p}}=\frac{1}{J}\left\{F_{\bar{p}} G_{y} H_{T}-G_{\bar{p}} F_{y} H_{T}\right\} \gtrless 0 \\
\frac{d T}{d \bar{p}}=\frac{1}{J}\left\{F_{y}\left[e^{-r y} D(\bar{p})-H_{\bar{p}} G_{z}\right]-F_{\bar{p}}\left[-D(\bar{p}) G_{y}-H_{y} G_{z}\right]\right\} \gtrless 0 .
\end{gathered}
$$

The effect on the life of the aggregate resource stock is also ambigous:

$$
\frac{d(T+y)}{d \bar{p}}=\frac{1}{J}\left\{F_{y}\left[e^{-r y} D(\bar{p})-H_{\bar{p}} G_{z}\right]-F_{\bar{p}}\left[G_{z} H_{T}-D(\bar{p}) G_{y}-H_{y} G_{z}\right]\right\} \gtrless 0 .
$$

However, the effects on the price path are unambigous (see equation (9)). First, an increase in capacity (a fall in $\bar{p}$ ) necessarily leads to a lower initial price:

$$
\frac{d p(0)}{d \bar{p}}>0 .
$$

Second, a fall in $\bar{p}$ lowers the price at which deposit $S_{2}$ begins to be exploited:

$$
\frac{d p(T)}{d \bar{p}}>0
$$

Proposition 2: An increase in the capacity of the clean energy sector has an ambiguous effect on the life of the aggregate resource stock, and it lowers the scarcity rent of both exhaustible resource stocks.

To obtain clearer results, let us consider the case of linear demand. 


\section{The special case of linear demand}

In the following, we assume that demand is linear:

$$
D[p(t)]=A-p(t)
$$

Then, taking into account equation (21), equation (3) becomes

$$
\int_{0}^{y}\left[A-\left(c_{2}+\left(\bar{p}-c_{2}\right) e^{r(\tau-y)}\right)\right] d \tau=y(A-\bar{p})+S_{2} .
$$

Differentiating totally, we obtain after some rearrangement,

$$
\frac{d y}{d \bar{p}}=-\frac{S_{2}}{\left(1-e^{-r y}\right)\left(\bar{p}-c_{2}\right)^{2}}<0 .
$$

Thus, an expansion in capacity $\bar{q}_{3}$, which leads to a fall in $\bar{p}$, lengthens the life of deposit 2 . Moreover, from equations (6) and (22), we can derive the effect of an increase in $\bar{p}$ on $z$ as

$$
\frac{d z}{d \bar{p}}=\frac{1}{r}\left(\frac{1}{c_{2}-c_{1}+\left(\bar{p}-c_{2}\right) e^{-r y}}\right)\left[e^{-r y}-r\left(\bar{p}-c_{2}\right) e^{-r y} \frac{d y}{d \bar{p}}\right]>0 .
$$

Thus, a fall in $\bar{p}$ shortens the phase during which both $q_{1}$ and $q_{3}$ are supplied to the market. To find the effect of an increase in $\bar{p}$ on $T$, insert the linear demand function (21) into equation (10), leading to

$$
\int_{0}^{T}\left[A-c_{1}-\left(c_{2}+\left(\bar{p}-c_{2}\right) e^{-r y}-c_{1}\right) e^{r(t-T)}\right] d t=S_{1}+z(A-\bar{p})
$$

where $y$ and $z$ are both functions of $\bar{p}$, with derivatives given by equations (22) and (23). Rearranging terms and totally differentiating leads to

$$
\begin{gathered}
{\left[A-c_{1}-\left(c_{2}+\left(\bar{p}-c_{2}\right) e^{-r y}-c_{1}\right) e^{-r T}\right] \frac{d T}{d \bar{p}}} \\
=\left\{-\left(\frac{1-e^{-r T}}{r}\right) r\left(\bar{p}-c_{2}\right) e^{-r y} \frac{d y}{d \bar{p}}+(A-\bar{p}) \frac{d z}{d \bar{p}}+\left(\frac{1-e^{-r T}}{r}\right) e^{-r y}\right\}-z .
\end{gathered}
$$

Consider the right-hand side (RHS) of equation (24). The sum of the terms inside the curly brackets $\{\ldots\}$ is positive. However, because $z$ is positive, the sign of the RHS seems ambiguous. On the left-hand side, the expression inside the square brackets [...] is ambiguous, though it is positive if $A$ is sufficiently large.

The effect of an increase in $\bar{p}$ on the life of the aggregate resource stock, $y+T$, is also 
ambiguous. The results shown in equations (22), (23), and (24) can be summarized in the following proposition.

Proposition 3: Under linear demand, an increase in the capacity of the clean energy sector (i.e., a decrease in $\bar{p}$ ) will lengthen the life of deposit 2, shorten the interval of simultaneous supply of $q_{1}$ and $q_{3}$, and has an ambiguous effect on the life of deposit 1 and of the aggregate resource stock. In the special case where $A$ is large and $z$ is very small (i.e., $S_{2}$ approaches $S_{2}^{\max }$ from below), an increase in capacity will shorten the life of deposit 1:

$$
\frac{d T}{d \bar{p}}>0
$$

An increase in the capacity of the renewable resource increases the extraction duration of the second exhaustible resource: $d y / d \bar{p}<0$ (equation (22)). This indicates that a capacity expansion of the renewable resource sector permits the stock of higher-cost resource $S_{2}$ to be spread over a longer period. In constrast, if $z$ is small and $A$ is large, we can state that $d T / d \bar{p}>0$ (equation (25)), and the effect of a capacity increase on the extraction duration of the low-cost stock $S_{1}$ is negative. This case is especially reasonable since we know that a capacity expansion reduces the energy price at the exhaustion point of $S_{1}$ (equation (20)), which indicates a faster extraction of $q_{1}$. Additionally, as with the subsidy, the capacity increase induces a reduction in the initial energy price, which also accelerates exhaustion (equation (19)).

Moreover, increased capacity leads to a reduction in the period of parallel supply of $q_{1}$ and $q_{3}: d z / d \bar{p}>0$ (equation (23)). Therefore, the capacity increase cannot alleviate the demand for $S_{1}$ and, consequently, weakening the capacity constraints leads to at least a weak green paradox with regard to the cheaper exhaustible resource. This holds irrespective of the effect on $t_{3}$, which is ambiguous. Nevertheless, it is not clear whether there will be an overall green paradox: $(d T / d \bar{p}+d y / d \bar{p})$ is ambiguous and further evaluation is necessary. ${ }^{6}$

\footnotetext{
${ }^{6}$ The described effect of an expansion of capacity in the case of a binding constraint cannot be used to infer about the actually observed capacity increase of renewable power production in some countries. For example, in the case of the German electricity market, binding technological, ecological, or geographical constraints to capacity are not yet reached. For instances, geographical restrictions on the installation of wind mills or sustainability restrictions regarding the usage of biomass are not operative yet. For the sake of simplicity, the present paper abstracts from any kind of dynamic transition process in the supply of renewable energy.
} 


\subsubsection{Effect of a tax on the low-cost exhaustible resource}

The effect of different tax schemes on exhaustible resources are evaluated in this and the next subsection. We first consider a tax on the low-cost exhaustible resource that causes an increase in the (tax-inclusive) constant marginal extraction costs of deposit $1 .^{7}$ The effect of a tax on the low-cost resource on the endogenous variables $(y, z, T)$ as well as on the price path, which is analogously modeled as a marginal increase in the extraction $\operatorname{costs} c_{1}$, can be computed from the following matrix equation

$$
\left[\begin{array}{ccc}
F_{y} & F_{z} & F_{T} \\
G_{y} & G_{z} & G_{T} \\
H_{y} & H_{z} & H_{T}
\end{array}\right]\left[\begin{array}{c}
d y \\
d z \\
d T
\end{array}\right]=\left[\begin{array}{l}
-F_{c_{1}} \\
-G_{c_{1}} \\
-H_{c_{1}}
\end{array}\right] d c_{1}
$$

where

$$
\begin{gathered}
F_{c_{1}}=0 \\
G_{c_{1}}=1-e^{r z}<0 \\
H_{c_{1}}=\int_{0}^{T} D^{\prime}[p(t)]\left(1-e^{r(t-T)}\right) d t<0 .
\end{gathered}
$$

In contrast to the calculations in Section 3.2.1, the results are unambiguous. First, the tax on deposit 1 does not change the length of the extraction period for deposit 2 :

$$
\frac{d y}{d c_{1}}=0
$$

This result in turn implies that the price at which extraction of deposit 2 begins is unaffected; see equation (5). Second, the tax lengthens the interval over which $q_{1}$ and $q_{3}$ are simultaneously supplied:

$$
\frac{d z}{d c_{1}}=\frac{1}{J}\left[F_{y}\left(-G_{c_{1}}\right) H_{T}\right]>0
$$

The extraction of the low cost deposit will be spread out over a longer period:

$$
\frac{d T}{d c_{1}}=\frac{1}{J}\left[F_{y} G_{z}\left(-H_{c_{1}}\right)-F_{y}\left(-G_{c_{1}}\right) H_{z}\right]>0 .
$$

Moreover, from equation (9), the initial price of the extracted resource will be raised,

\footnotetext{
${ }^{7}$ Even though this case does not appear to have much practical relevance, many authors, including Sinn (2008), show that a credible commitment to a tax rate that is high today but decreases over time is the best strategy for slowing down extraction of fossil fuels. Therefore, we examine that situation here with the simplification that we assume a tax on the low-cost resource but not on the high-cost resource that will be extracted later.
} 
though by a smaller amount than the increase in tax:

$$
1>\frac{d p(0)}{d c_{1}}=1-e^{-r T}>0
$$

Only the effect on the time at which the renewable energy is made available, $t_{3}$, is ambiguous:

$$
\frac{d t_{3}}{d c_{1}}=\frac{d T}{d c_{1}}-\frac{d z}{d c_{1}}=\frac{1}{J}\left[F_{y} G_{z}\left(-H_{c_{1}}\right)+F_{y} G_{c_{1}} H_{z}\right]-\frac{1}{J}\left[F_{y}\left(-G_{c_{1}} H_{T}\right] \gtrless 0 .\right.
$$

But since the exhaustion time for the cheaper resource, $T$, is delayed, the ambiguous sign of equation (31) is of no consequence with regard to the green paradox. ${ }^{8}$ The results are summarized in Proposition 4.

Proposition 4: While a tax on the low-cost resource has no effect on the extraction duration of the high-cost resource, it does result in a higher initial price of energy. Moreover, the overall period of extraction from the cheaper resource lengthens, leading to slower extraction of the cheaper exhaustible resource during the initial phase $\left[0, t_{3}\right)$ both due to an increase in $T$ and an increase in $p(0)$. Thus, there is neither a weak nor an overall green paradox. (The ambiguous effect on the interval $\left[0, t_{3}\right)$ is of no consequence for the green paradox results.)

This result can be understood as follows (see also the price path of this scenario illustrated in Section 4.2): a tax on the cheaper exhaustible resource is equivalent to an increase in $c_{1}$. From $d y / d c_{1}=0$ (equation (27)), we know that a tax on the low-cost resource has no effect on how long it will take to exhaust $S_{2}$. Parallel to the case of subsidizing the renewable resource, from the invariance of $y$ it follows that $p_{2}$ is unchanged, see equation (5). When such is the case, the aggregated supply of energy over the length of time $y$ equals the demand. Moreover, $d T / d c_{1}>0$ (equation (29)) implies that the tax increases the time span of extraction of $S_{1}$ by $\left(T^{*}-T\right)$. Together with $p^{*}(0)>p(0)$ (equation $(30)$ ), this means that the price level $p_{2}$ (at which the second deposit begins to be exploited) is reached later and the exhaustible resource $S_{1}$ is available longer. The price path during $[0, T)$ is flatter and the price level is higher such that extraction of $S_{1}$ is spread over a longer period of time. Therefore, the old and the new price path during the extraction of $S_{1}$ must intersect. ${ }^{9}$ Nevertheless, the effect on $t_{3}$ is not clear. Even though we know from $d z / d c_{1}>0$ (equation (28)) that the time span

\footnotetext{
${ }^{8}$ Thus, our result for the multi-resource case supports Sinn's (2008) proposition that "high tax now and low tax later is good for the environment."

${ }^{9}$ The "intersection" is easily explained by the fact that the two price paths correspond to different values of $c_{1}$.
} 
of simultaneous use of $q_{1}$ and $q_{3}$ increases, we do not know whether the production of the clean energy will begin earlier or later, as the sign of $d t_{3} / d c_{1}$ (equation (31)) is ambiguous. In conclusion, the imposition of a constant unit tax on the low-cost exhaustible resource gives rise to neither a weak green paradox ( since $\left.d p(0) / d c_{1}>0\right)$ nor an overall green paradox (since $d T / d c_{1}+d y / d c_{1}>0$ ).

\subsubsection{Effect of a tax on the extraction of the high-cost exhaustible resource}

We now examine how a tax on (an increase in) $c_{2}$ affects the endogenous variables. ${ }^{10}$ This can be computed from the following matrix equation

$$
\left[\begin{array}{lll}
F_{y} & F_{z} & F_{T} \\
G_{y} & G_{z} & G_{T} \\
H_{y} & H_{z} & H_{T}
\end{array}\right]\left[\begin{array}{c}
d y \\
d z \\
d T
\end{array}\right]=\left[\begin{array}{l}
-F_{c_{2}} \\
-G_{c_{2}} \\
-H_{c_{2}}
\end{array}\right] d c_{2}
$$

where

$$
\begin{gathered}
F_{c_{2}}=\int_{0}^{y} D^{\prime}[p(t)]\left(1-e^{r(\tau-y)}\right) d t<0 \\
G_{c_{2}}=-\left(1-e^{-r y}\right)<0 \\
H_{c_{2}}=\int_{0}^{T} D^{\prime}[p(t)]\left(1-e^{-r y}\right) e^{r(t-T)} d t<0 .
\end{gathered}
$$

\section{The general case}

Even though the signs of the above partial derivatives are unambiguous, some results of the comparative statics are ambiguous. The tax on the high cost exhaustible resource will lead to a lengthening of its extraction period:

$$
\frac{d y}{d c_{2}}=\frac{1}{J}\left[-F_{c_{2}} G_{z} H_{T}\right]>0 .
$$

However, the effect on the period of simultaneous use of green energy and the low cost resource is not clear,

$$
\frac{d z}{d c_{2}}=\frac{1}{J}\left[F_{y}\left(-G_{c_{2}}\right) H_{T}-\left(-F_{c_{2}}\right) G_{y} H_{T}\right] \gtrless 0
$$

\footnotetext{
${ }^{10}$ Increasing taxes on fossil fuels is common practice throughout the world, not only for fiscal reasons, but due to growing awareness of the consequences of climate change and the exhaustibility of fossil fuels. However, according to Sinn (2008) and others, this practice causes detrimental green paradox effects.
} 
and the effect on the period of exploitation of the low cost deposit is also ambiguous:

$$
\frac{d T}{d c_{2}}=\frac{1}{J}\left[F_{y} G_{z}\left(-H_{c_{2}}\right)+\left(-F_{c_{2}}\right) G_{y} H_{z}-\left(-F_{c_{2}}\right) G_{z} H_{y}-F_{y}\left(-G_{c_{2}}\right) H_{z}\right] \gtrless 0 .
$$

We summarize the results in Proposition 5.

Proposition 5: A tax on the high-cost exhaustible resource deposit lengthens the exploitation period of this deposit, but has an ambiguous effect on the life of the lower cost resource and of the aggregate resource stock.

Therefore, to obtain sharper results, we consider the case of linear demand in the following.

\section{The special case of linear demand}

In case of a linear demand function as formulated in equation (21), the partial derivatives have the following signs:

$$
\begin{aligned}
\frac{d y}{d c_{2}}>0 \\
\frac{d z}{d c_{2}}>0 \\
\frac{d T}{d c_{2}}>0 \\
\frac{d p(0)}{d c_{2}}>0 \\
\frac{d t_{3}}{d c_{2}}<0
\end{aligned}
$$

From equations (33)-(37), we can now state Proposition 6.

Proposition 6: Under linear demand, a tax on the high-cost resource extraction (an increase of $c_{2}$ ) will lengthen the life of both deposits 1 and 2 , lengthen the interval of simultaneous supply of $q_{1}$ and $q_{3}$, and therefore increase the life of the aggregate resource stock.

The effects can be understood as follows: a change in the marginal extraction costs has no effect on the price ceiling determined by $D(\bar{p})=\bar{q}_{3}$. Therefore, when $\bar{p}$ and $\bar{q}_{3}$ are given, a longer (slower) extraction of deposit 2 , as indicated by $d y / d c_{2}>0$ (equation (33)), is possible only when demand is reduced during the considered time span. This can be reached 
by an overall price level increase. From

$$
\frac{d p(T)}{d c_{2}}>0,
$$

we know that $p\left(T^{*}\right)>p(T)$. This means that extraction from the high cost deposit starts from a higher price level and $q_{2}(t)$ is already initially lower. Therefore, to have $S_{2}$ exhausted

at $\bar{T}^{*}>\bar{T}$, the price path is flatter, such that $y^{*}>y$. The changes in the depletion path of deposit 1 can be explained analogously: a flatter price path, and a longer extraction period $\left(d T / d c_{2}>0\right.$; see equation (35)) with a higher initial price $\left(d p(0) / d c_{2}>0\right.$; see equation (38)). This means that $S_{1}$ is more valuable to the resource owner (higher price and higher scarcity rent). Moreover, even though the tax on the high-cost resource postpones production of green energy $\left(d t_{3} / d c_{2}>0\right.$; see equation (37)), the length of simultaneous production of $q_{1}$ and $q_{3}$ increases $\left(d z / d c_{2}>0\right.$; see equation (34)). In the end, neither a weak nor an overall green paradox is found.

In the following section, the comparative static policy analysis is complemented by a numerical analysis, which allows us to link the theoretical model to a concrete example of the fossil fuel market and derive precise results, which are missing from the analytical part. Moreover, we conduct a welfare analysis to discover the social consequences of the different scenarios. To this end, we introduce two different explicit damage functions as well as a situation where the various deposits have different carbon content. This extended welfare analysis allows us to draw further conclusions regarding the strong green paradox effect defined by Gerlagh (2011).

\section{Numerical analysis}

In the following, we provide a numerical illustration of the previous model. While we are not really calibrating the model in the sense of using numerical values that are derived from real world date, the relative magnitudes of the numbers we use are intended to reflect, in a stylised manner, real-world relative magnitudes. Our numerical excercise allows not only the derivation of unambiguous results, but also a concrete illustration of the relevant effects. We derive the accumulation paths of anthropogenic carbon in the atmosphere and compare their resulting social consequences. Additionally, we later relax the assumption of zero decay and instead assume a positive depreciation of anthropogenic carbon. The analysis begins by describing the fossil fuel market example in Section 4.1. The numerical results are derived in Section 4.2, followed by a welfare analysis in Section 4.3. 


\subsection{The fossil fuel market}

The parameters are chosen so as to reflect, in a stylised manner, the relationships between marginal extraction costs for conventional oil, unconventional oil, and advanced biofuel. ${ }^{11}$ We continue to assume the case of linear demand, $D[p(t)]=A-p(t)$ (see equation (21)), and that $\bar{p}>c_{3}$. We choose $A=20, \bar{p}=15, r=0.01$. We set $c_{1}=0.75, c_{2}=1.75$, and $c_{3}=4$. This reflects the cost structure observed in oil markets: biofuel has the highest, unconventional oil has medium, and conventional oil the lowest production costs. Then $\bar{q}_{3}=A-\bar{p}=5$. Moreover, we specify the stock sizes $S_{1}$ and $S_{2}$ because we need these to compute the pollution stock. First, we need to make sure that $S_{2}<S_{2}^{\max }$. This means that we first have to compute the value $S_{2}^{\max }$ from our specifications of the cost parameters $c_{1}$, $c_{2}$, and $c_{3}$ and of the capacity $\bar{q}_{3}$ (which is equal to $A-\bar{p}$ ). Let us assume that $S_{2}=900$ and $S_{1}=700$, which reflects the fact that there is more unconventional than conventional oil available. From Condition 2 with $S_{2}^{\max }=1249$ (approximately), it follows that $S_{2}=900$ does indeed satisfy the condition $S_{2}<S_{2}^{\max }{ }^{12}$

\subsection{Derivation of numerical results}

We now show how we derive numerical results for the base case. (The results of the different policy scenarios can be derived analogously.) Wefirst calculate the length of Phase $3, y=\bar{T}-T=144.30$. Second, we solve for the length of Phase $2, z \equiv T-t_{3}$, which is the time interval over which the lowest-cost deposit and the renewable energy are available simultaneously. From equation (6), $z=23.96$. Next, we solve for $T$ (the time at which deposit 1 is exhausted) from equation (10), then, $T=51.18$.

Moreover, the length of Phase $1, t_{3}$, and the total length of Phases 1-3, $\bar{T}$, can be calculated as $t_{3}=T-z=27.22$ and $\bar{T}=T+y=195.48$.

From equation (9), the equilibrium price at time $t$ (for $0 \leq t \leq T$ ) is $p(t)=1.75+$ $e^{0.01(t-51.18)}+13.25 e^{0.01(t-195.48)}$; specifically, $p(0)=3.23, p(T)=4.88$, and, as expected, $p\left(t_{3}\right)=4=c_{3}$. Moreover, from equation (2), the equilibrium price path for $T \leq t \leq \bar{T}$ is $p(t)=1.75+13.25 e^{0.01(t-195.48)}$.

Table 1 sets out the results of the numerical analysis for the different policy scenarios and the base case in the chosen numerical example. This allows comparing the effects of

\footnotetext{
${ }^{11}$ See, e.g., www.eia.gov and IEA(2012).

${ }^{12}$ This condition is also fulfilled for all following model specifications.
} 
the respective policy measures on extraction speed and duration of the fossil fuels. In our first policy scenario, there is a subsidy on the green energy at the rate 1 per unit (e.g. one Euro per kilowatt-hour); consequently, the (marginal) production costs of the green energy decrease from 4 to 3 per unit. In an alternative policy scenario, there is a capacity expansion from 5 to 6 ; therefore, $\bar{p}$ decreases from 15 to 14 . In a third policy scenarion, the tax on the low-cost exhaustible resource increases from 0 to 1 , such that the (marginal) production cost of the green energy increases from 0.75 to 1.75 per unit. Finally, in the fourth scenario, the tax on the high-cost exhaustible resource is increased from 0 to 1 ; therefore, the (marginal) production cost of the green energy increases from 1.75 to 2.75 per unit.

Recall that in Proposition 3, an increase in capacity will increas $y$, may reduce $T$, and the effect on $\bar{T} \equiv T+y$ is ambiguous. Our numerical results show that an increase in the capacity of the green substitute does not reduce $\bar{T}$ (indicating that there is no overall green paradox). This is because numerically $d \bar{T} / d \bar{p}<0$ (which means $\bar{T}$ increases). Moreover, we find that $d t_{3} / d \bar{p}<0$. The reason for the positive effect on $t_{3}$ is that $p(0)$ is lower than before; therefore, it takes longer for $p(t)$ to reach $c_{3}$. However, with $d y / d \bar{p}<0$, it also takes longer to exhaust the aggregate resource stock than is the case in the base scenario.

With regard to the effect of a tax on the low-cost resource on $t_{3}$, the numerical analysis shows that $d t_{3} / d c_{2}>0$ (Table 1 , fifth column). Parallel to the previous explanation, the slight increase in $t_{3}$ is mostly explained by the increase in $p(0)$ that flattens the price path. This can be summarized in Proposition 7.

Proposition 7: In our numerical simulation, a capacity increase of the green energy substitute leads to earlier production of green energy ( $t_{3}$ decreases) and does not produce an overall green paradox effect since it induces an increase of $\bar{T}$.

Figure 1 illustrates how the different policy measures of the chosen numerical example affect the price paths. In the figure, the price paths of the different policy scenarios are compared with the base case price path. The policy measures reduce the price level for most time periods. However, we know from Table 1 that this does not lead to a decrease in the overall extraction duration of the exhaustible resources.

Concerning the price path, we know that in the standard model, price paths do not cross. However, in the case where there exists a capacity constraint on the green energy, we have shown in Proposition 4 that a tax on the extraction of the low cost resource leads to a new price path that crosses the old one from above. The price path behavior is striking in the case of a capacity increase of green energy (Figure 1b). First, the capacity increase reduces 

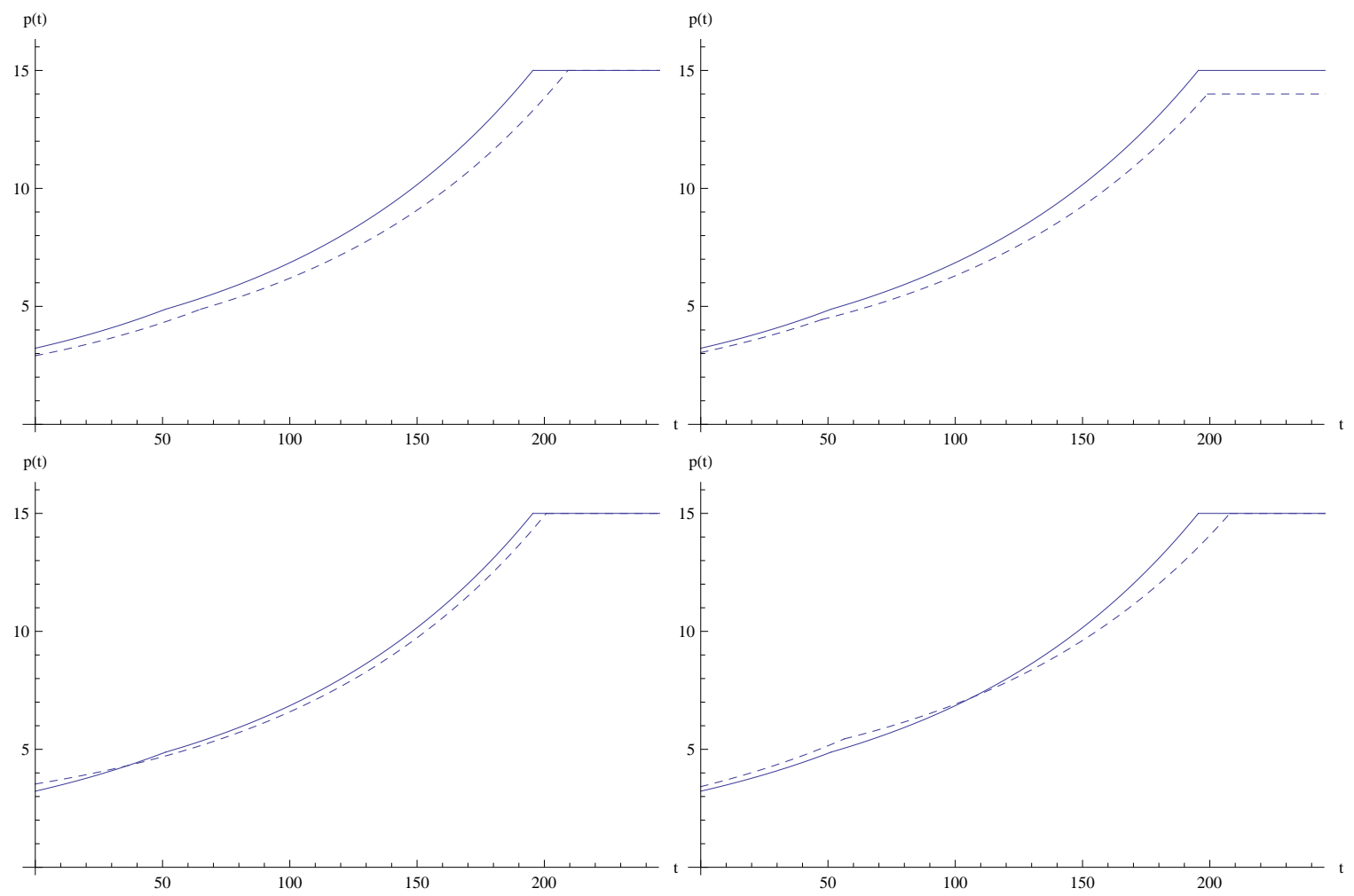

Figure 1: Price paths of the policy scenarios compared with the base scenario

the capacity-constrained choke price. Second, the increase in capacity can overcompensate the higher demand resulting from the lower price path such that the overall extraction duration of the exhaustible resources increases (see also Table 1) even though an overall higher demand needs to be satisfied.

In the following, the emission paths and the resulting welfare effects in terms of damages from accumulated anthropogenic carbon pollution in the atmosphere will be determined. We will calculate accumulated emissions in the situation where the various deposits have different carbon contents, and also for with a positive decay rate for the atmospheric carbon, and compare the effects of various policies on the social cost, under two alternative specifications of a damage function. This permits us to derive explicit social consequences resulting from carbon use under various policy scenarios, allowing for both flow and stock damages.

\subsection{Welfare analysis}

In a first step, the decay rate of atmospheric carbon is assumed to be zero. In a second step, the zero depreciation rate assumption is relaxed and a more realistic model is introduced in which the atmosperic carbon stock partially decays from the atmosphere over time. The 
positive decay rate is based on Archer (2005) and others who analyze the accumulated stock of emissions in the atmosphere. We study both the cases of linear and convex social damage functions, and compare the present value damages of the different policy scenarios. Accumulated emissions depend not only on the speed of extraction. A faster accumulating stock brings higher damages closer to the present. With a positive decay rate, different mechanisms influence the welfare effects of climate policy. Later in the analysis, these are identified and discussed in more detail with regard to their implications for the analysis as well as for policymakers. ${ }^{13}$

\subsubsection{Emission Paths}

For our welfare analysis, we must first compute the emission paths of the different policy scenarios for the chosen numerical example. To calculate them, we have to specify the emission parameters of the extracted exhaustible resources. In the following, we assume that $\eta_{1}=1$ is the emission parameter of the low-cost exhaustible resource and $\eta_{2}=2$ is the one for the high-cost exhaustible resource. For our fuel market example, this reflects the fact that conventional oil is not only cheaper, but also has lower emissions during extraction and production, than unconventional oil.

During the first extraction phase, i.e., the time interval $\left[0, t_{3}\right)$, all energy comes from deposit 1. Since extraction from this deposit must equal energy demand, emissions from the consumption of $q_{1}(t)$ are $\varepsilon_{1}(t)=\eta_{1} q_{1}(t)$. Over the time interval $\left[t_{3}, T\right)$, Phase 2 , energy demand is met by extraction from deposit 1 and by renewable energy supply $\bar{q}_{3}=A-\bar{p}=2$ such that emissions at any time $t$ in the interval $\left[t_{3}, T\right)$ are $\varepsilon(t)=\eta_{1}\left(Q(t)-\bar{q}_{3}\right)$. Over the time interval $[T, \bar{T})$, Phase 3, energy demand is met by extraction from deposit 2 and by renewable energy supply $\bar{q}_{3}=2$. Thus extraction from deposit 2 at any time $t$ during the interval $[T, \bar{T})$ is $q_{2}(t)=D[p(t)]-\bar{q}_{3}$ and emissions from consumption of $q_{2}$ at any $t$ in $[T, \bar{T})$ are $\varepsilon_{2}(t)=\eta_{2}\left(Q(t)-\bar{q}_{3}\right)$.

Figure 2 shows how the different policy measures affect $\mathrm{CO}_{2}$ emission streams compared to the base case. In the subsidy scenario, emissions tend to be higher than in the base case (since the price is lower), except that $z$ is larger and $t_{3}$ occurs sooner. This compensates for higher emissions in the beginning, such that the total extraction period of the cheaper resource increases (the exhaustion duration of the expensive resource being constant). In

\footnotetext{
${ }^{13}$ In this paper, we analyze welfare effects only partially. We focus on social damages from accumulated anthropogenic carbon pollution in the atmosphere. We do not take into account other effects on production or consumption. Therefore, under this restricted sense, a welfare effect of a policy measure is positive if it decreases the pollution damage compared to the baseline scenario without policy intervention.
} 

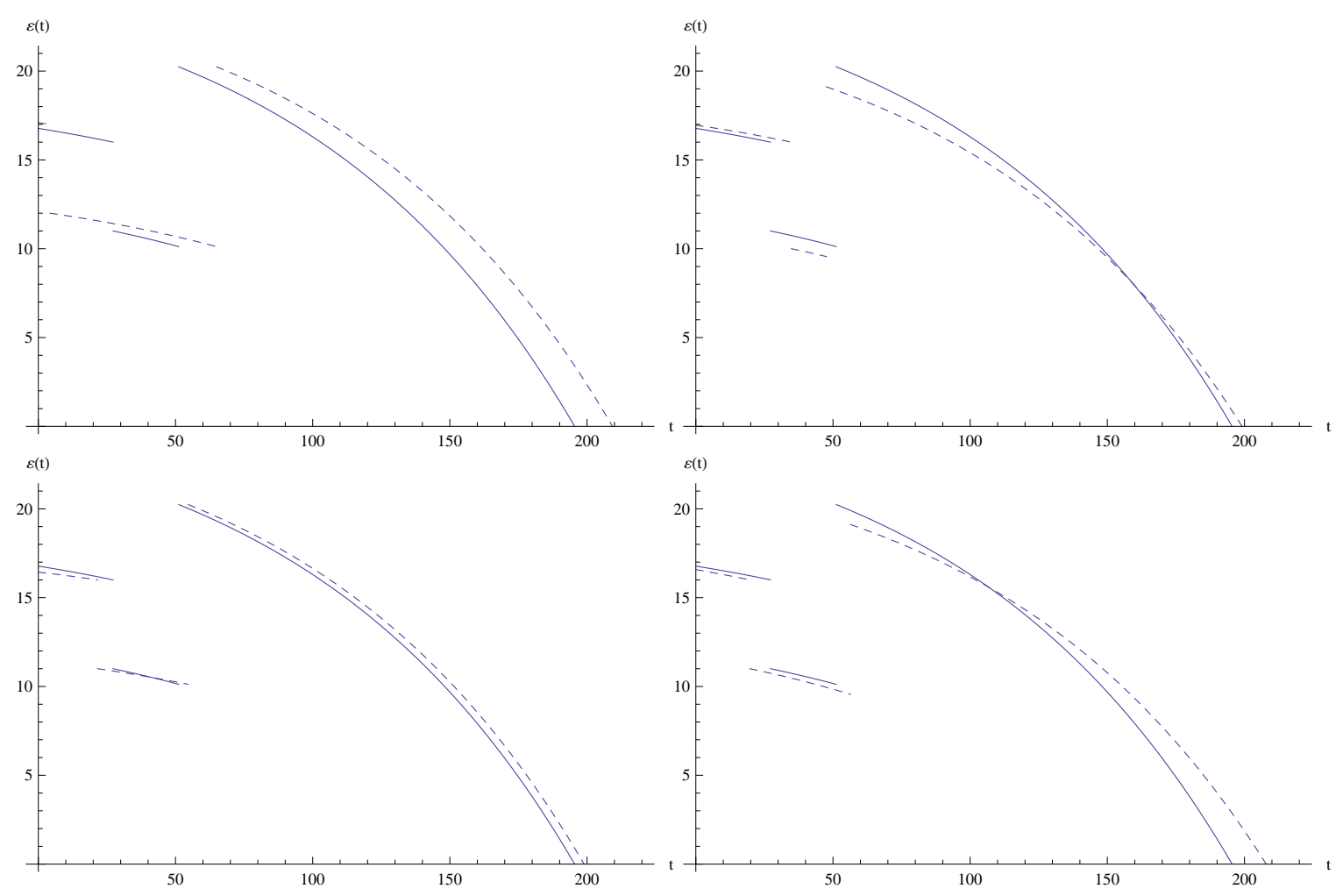

Figure 2: Emission paths of policy scenarios compared with base scenario

the capacity expansion scenario, a slightly lower price path leads to slightly higher emissions during the extraction period of the low-cost deposit. Moreover, $z$ is shorter compared to the base case, but emissions are lower due to the increased capacity. Nevertheless, the increased capacity cannot stretch the first extraction period until $T$; however, emissions from the dirtier resource can be slowed down, at least until the emission paths cross. In total, the emission paths cannot only be flattened regarding the dirty energy source, but the overall emission period can be extended. In the first tax scenario, due to the higher initial price, emissions can be reduced initially and their path can be flattened with an almost identical $t_{3}$ even though emissions during $z$ increase. Since there are no changes in the emission flows from the dirty energy good, the overall effect on $\bar{T}$ is positive. Finally, taxing the dirty energy good has effects similar to those found when taxing the cheap exhaustible energy good and lowers the periodical emissions during the first extraction phase (including $z$ ). In the second phase, which therefore starts later, emissions start lower but since the path is flatter, end up higher. Also in this policy scenario, the overall effect on $\bar{T}$ is positive. ${ }^{14}$

\footnotetext{
${ }^{14}$ The calibration of the model determines the quantitative but not the qualitative effect of the policy measures. For example, the chosen emission intensities influence the extent of the changes in the emission levels associated with changes in the fuel mix.
} 


\subsubsection{Pollution and damages with a zero decay rate}

In this section, a decay rate of zero is assumed, which means that once anthropogenic $\mathrm{CO}_{2}$ has been emitted into the atmosphere, it remains there forever. $\delta=0$ can more broadly be interpreted as an approximation of a $\delta$ close to 0 meaning that the potentially existing decay of atmospheric carbon is just not relevant in the considered period of time. ${ }^{15}$ Moreover, since there is no decay, the volume of pollution $V(t)$ is identical to accumulated emissions $E(t)$. In the following, the welfare analysis is conducted for the baseline scenario and can be performed analogously for the other policy scenarios.

Over the time interval $\left[0, t_{3}\right)$ in Phase 1 , the accumulated stock pollution (which is the accumulated stock of anthropogenic carbon in the atmosphere) at time $t^{\prime}$ (for $0 \leq t^{\prime} \leq t_{3}$ ) is

$$
\begin{aligned}
& V^{\text {phase } 1}\left(t^{\prime}\right)=\int_{0}^{t^{\prime}} \eta_{1}\left[A-c_{1}-\left(c_{2}-c_{1}+\left(\bar{p}-c_{2}\right) e^{-r y}\right) e^{r(t-T)}\right] d t \\
= & \int_{0}^{t^{\prime}} 1.75\left(17.25+e^{0.01(t-40.37)}+14.25 e^{0.01(t-187.60)}\right) d t \text { for } t \leq t_{3} .
\end{aligned}
$$

Rearranging this expression gives

$$
V^{\text {phase } 1}\left(t^{\prime}\right)=\eta_{1}\left[A-c_{1}\right] t^{\prime}-\eta_{1}\left(c_{2}-c_{1}+\left(\bar{p}-c_{2}\right) e^{-r y}\right) e^{-r T}\left(\frac{e^{r t^{\prime}}-1}{r}\right) .
$$

Analogously, over the time interval $\left[t_{3}, T\right)$ in Phase 2, the stock of pollution at any time $t^{\prime} \in\left[t_{3}, T\right)$ is

$$
V^{\text {phase } 2}\left(t^{\prime}\right)=\eta_{1}\left(A-c_{1}-\bar{q}_{3}\right) t^{\prime}+\eta_{1} \bar{q}_{3} t_{3}-\eta_{1}\left(c_{2}-c_{1}+\left(\bar{p}-c_{2}\right) e^{-r y}\right) e^{-r T}\left(\frac{e^{r t^{\prime}}-1}{r}\right)
$$

and from the results presented in Table 4.1, we can calculate $V(T)=700$, which is, as expected, the size of $S_{1}$.

Over the time interval $\left[T, \bar{T}\right.$ ) in Phase 3 , the accumulated stock pollution at time $t^{\prime}$ (for $T \leq t^{\prime} \leq \bar{T}$ ) is (decay rate of pollution stock is still zero):

$$
V^{\text {phase } 3}\left(t^{\prime}\right)=V(T)+\eta_{2}\left(A-c_{2}-\bar{q}_{3}\right)\left(t^{\prime}-T\right)-\eta_{2}\left(\bar{p}-c_{2}\right) e^{-r(T+y)}\left(\frac{e^{r t^{\prime}}-e^{r T}}{r}\right) .
$$

Again, from Table 4.1, we can calculate $V(\bar{T})=2.500$, which is obviously once $S_{1}$ plus twice

\footnotetext{
${ }^{15}$ In line with, e.g., Sinclair (1994) and van der Ploeg and Withagen (2011), $\delta$ can be assumed to be small enough to be ignored, as a first approximations.
} 
the size of $S_{2}$.

Finally, in Phase 4, which lasts from $t=\bar{T}$ until infinity, the accumulated pollution stays in the atmosphere forever as

$$
V^{\text {phase } 4}(t)=V^{\text {phase } 4}(\bar{T})=\eta_{1} S_{1}+\eta_{2} S_{2}=2.500
$$

In the following, the damages from the accumulated atmospheric pollution are analyzed. If the damage function $C[V(t)]$ is linear, say $C[V(t)]=\theta V(t)$ (and is also equal to $\theta E(t)$, see above), then damage at time $0 \leq t^{\prime} \leq t_{3}$ is $C[V(t)]=\theta \eta_{1} q_{1}(t)$ and analogously for the other extraction phases. Together with equations (39) - (42), the resulting total discounted stream of damages from $t=0$ to $\infty$ is:

$$
\begin{gathered}
D\left(t_{0}\right)=\int_{0}^{t_{3}} e^{-r t} \theta V^{\text {phase } 1}(t) d t+\int_{t_{3}}^{T} e^{-r t} \theta V^{\text {phase } 2}(t) d t+\int_{T}^{\bar{T}} e^{-r t} \theta V^{\text {phase } 3}(t) d t \\
+\theta V^{\text {phase } 4}(\bar{T})\left(\frac{e^{-r \bar{T}}-1}{r}\right)
\end{gathered}
$$

Due to the linearity of the assumed damage function, we can calculate the discounted damages for the different policy scenarios without any further specification of $\theta$. Inserting the values of the numerical analysis into equation (43) allows us to directly compare the welfare effects of the different policy scenarios with the business as usual case. Comparing the discounted damages for the period between 0 and infinity for the different policy scenarios gives

$$
D^{\text {tax } 2}\left(t_{0}\right) \leq D^{\text {subsidy }}\left(t_{0}\right) \leq D^{\text {tax } 1}\left(t_{0}\right) \leq D^{\text {base case }}\left(t_{0}\right) \leq D^{\text {capacity }}\left(t_{0}\right)
$$

where $D^{\text {subsidy }}\left(t_{0}\right)$ stands for damages in the policy scenario with subsidization of the renewable substitute at $t=0, D^{\operatorname{tax} 2}\left(t_{0}\right)$ for the scenario where the high-cost exhaustible resource is taxed, $D^{\operatorname{tax} 1}\left(t_{0}\right)$ for the scenario where the low-cost exhaustible resource is taxed, $D^{\text {capacity }}\left(t_{0}\right)$ for the scenario where there is a capacity increase of the renewable substitute, and $D^{\text {base case }}\left(t_{0}\right)$ for the base case scenario. ${ }^{16}$

\footnotetext{
${ }^{16}$ Note, however, that these results are based on a partial analysis. Consequently, the measures are not easy to compare (see next section).
} 
It is interesting to observe that the damages in the scenario with a capacity expansion are higher than in all other scenarios. This is because the capacity expansion, which comes into affect in the future, at time $t_{3}$, lowers the initial price of energy, $p(0)$, leading to increased demand for energy for the period $\left[0, t_{3}\right]$, and hence greater pollution damages earlier on.

What happens now when the damage function is convex? For example, if the damage function is quadratic, say

$$
D[V(t)]=a \frac{V(t)^{2}}{b}
$$

as in van der Ploeg and Withagen (2011), with $a=0.00012$ and $b=2$, we can also compute a similar integral of discounted damages. If we continue to assume that the decay is zero, the volume of pollution $V(t)$ continues to be equal to accumulated emissions $E(t)$. Calculating and comparing the present value discounted damages, we receive qualitatively the same results, the same order, as in (44).

The inequality (44), derived under the assumption that the decay rate is $\delta=0$, applies to both the linear and the quadratic damage functions, and indicates that all policy measures, except the capacity increase, reduce the damages of carbon emissions compared to the base case situation. The effect of a capacity expansion is negative because a greater capacity induces a fast extraction of $S_{1}$. Since $r>0$, near-term emissions are more important for the welfare and this first green paradox effect cannot be compensated for by the resource-saving effect of a capacity increase on $S_{2}$ (relatively high $y$ ). Regarding the tax on the high-cost exhaustible resource, we find that it induces a reduction of the extraction speed (leading to a higher $\bar{T}$ ), and both $T$ and $y$ become larger. This results in lower damages compared to the baseline scenario. Subsidizing green energy also has positive welfare effects: for $t_{3}, T$, and $\bar{T}$, subsidization performs even better than the tax on the high-cost exhaustible resource. However, the reason the overall positive effect is smaller is that emissions in the beginning are higher for the subsidy case (since $p(0)$ is smaller). A tax on the low-cost exhaustible resource also reduces damages, but since $z$ is relatively short and $t_{3}$ relatively high, the positive effects are not very strong.

To this point, for both types of damage function, the welfare analysis implies that green energy policy measures can be either welfare increasing or detrimental, depending on how they affect the extraction behavior of the resource owners. Of course, the results depend on the model's underlying assumptions and parameter specifications. One strong assumption is the decay rate of zero. Therefore, in the next section, a welfare analysis employing a positive decay rate of atmospheric emissions is conducted. 


\subsubsection{Pollution and damages with a positive decay rate}

In this section, we assume a positive depreciation rate for carbon stock in the atmosphere, in accordance with Archer (2005). This is arguably a more realistic scenario. Indeed, Archer (2005) and Houghton et al. (1990, 1992) explain (though in a highly simplified way) that a fraction of the anthropogenic carbon emissions that are in the atmosphere re-enter the carbon cycle again and are absorbed by different carbon sinks, mostly the oceans. ${ }^{17}$ This means that although a fraction of the anthropogenic atmospheric carbon stock (let's call it $\alpha$ ) will stay in the atmosphere forever, the other part $(1-\alpha)$ will depreciate slowly over time at a positive rate $\delta$. This phenomenon has been discussed in the resource economics literature (see, e.g., Hoel, 2011; Hoel and Kverndokk, 1998; Farzin and Tahvonen, 1996). For the sake of simplicity, the rate of decay $\delta$ is assumed to be constant over time. Based on these considerations, for each emitted ton of $\mathrm{CO}_{2}$ at time $t$, the resulting amount of $\mathrm{CO}_{2}$ in the atmosphere at time $\tau>t$ is approximated by $\alpha+(1-\alpha) e^{-\delta(\tau-t)}\left(\right.$ Hoel, 2011). ${ }^{18}$

In addition, since there is positive decay, the accumulated emissions $E(t)$ always exceeds the volume $V(t)$ for all $t>0$. This means that total pollution in the atmosphere in the first phase with $t \in\left[0, t_{3}\right)$ is

$$
V^{\text {phase } 1}(t)=\alpha \eta_{1} \int_{0}^{t} q_{1}(\tau) d \tau+(1-\alpha) \eta_{1} e^{-\delta t}\left(\int_{0}^{t} q_{1}(\tau) e^{\delta \tau} d \tau\right)
$$

For $t \geq t_{3}$, the term $\alpha \eta_{1}[\ldots]$ with $t=t_{3}$, which we will call $a_{1}\left(t_{3}\right)$, stays constant and only the term $(1-\alpha) \eta_{1} e^{-\delta t}[\ldots]$ with $t=t_{3}$ (henceforth, $\left.b_{1}\left(t_{3}\right)\right)$ further depreciates, resulting in $b_{1}\left(t_{3}\right) e^{-\delta\left(t-t_{3}\right)}$ for $t>t_{3}$.

Total pollution in the second phase with $t \in\left[t_{3}, T\right)$ is:

$$
\begin{aligned}
& V^{\text {phase } 2}(t)=a_{1}\left(t_{3}\right)+b_{1}\left(t_{3}\right) e^{-\delta\left(t-t_{3}\right)} \\
& +\alpha \eta_{1} \int_{t_{3}}^{t}\left(q_{1}(\tau)-\bar{q}_{3}\right) d \tau+(1-\alpha) \eta_{1} e^{-\delta\left(t-t_{3}\right)}\left(\int_{t_{3}}^{t}\left(q_{1}(\tau)-\bar{q}_{3}\right) e^{\delta\left(\tau-t_{3}\right)} d \tau\right)
\end{aligned}
$$

Analogous to the case of $t \in\left(0, t_{3}\right)$ with $t \geq T$, the term $\alpha \eta_{1}[\ldots]$ for $t=T$, which we will call $a_{2}(T)$, stays constant and only the term $(1-\alpha) \eta_{1} e^{-\delta\left(t-t_{3}\right)}[\ldots]$ with $t=T$ (henceforth, $b_{2}(T)$ ) further depreciates, resulting in $b_{2}(T) e^{-\delta(t-T)}$ for $t>T$.

\footnotetext{
${ }^{17}$ For simplicity, we abstract from any lags between emission production, pollution accumulation, and damages as described, for example, in Houghton et al. (1990, 1992).

${ }^{18}$ Since the decay rate might not be constant over time, this can be seen as an approximation of the findings of Houghton et al. (1990, 1992), who reported that the decay rate of atmospheric carbon declines over time depending on the saturation of the oceans.
} 
Total pollution during the third phase with $t \in[T, \bar{T})$ is:

$$
\begin{aligned}
& V^{\text {phase } 3}(t)=a_{1}\left(t_{3}\right)+a_{2}(T)+b_{1}\left(t_{3}\right) e^{-\delta\left(t-t_{3}\right)}+b_{2}(T) e^{-\delta(t-T)}+\alpha \eta_{2} \int_{T}^{t}\left(q_{2}(\tau)-\bar{q}_{3}\right) d \tau \\
& +(1-\alpha) \eta_{2} e^{-\delta(t-T)}\left(\int_{T}^{t}\left(q_{2}(\tau)-\bar{q}_{3}\right) e^{\delta(\tau-T)} d \tau\right)
\end{aligned}
$$

As before, for $t \geq \bar{T}$, the term $\alpha \eta_{2}[\ldots]$ with $t=\bar{T}$, which we will call $a_{3}(\bar{T})$, stays constant and only the term $(1-\alpha) \eta_{2} e^{-\delta(t-T)}[\ldots]$ with $t=\bar{T}$ (henceforth, $b_{3}(\bar{T})$ ) further depreciates, resulting in $b_{3}(\bar{T}) e^{-\delta(t-\bar{T})}$ for $t>\bar{T}$.

Moreover, from $t=\bar{T}$ on (Phase 4), there is no further anthropogenic $\mathrm{CO}_{2}$ emitted in the atmosphere. Therefore, total pollution at $t$ with $t \in[\bar{T}, \infty)$ is:

$$
V^{\text {phase } 4}(t)=a_{1}\left(t_{3}\right)+a_{2}(T)+a_{3}(\bar{T})+b_{1}\left(t_{3}\right) e^{-\delta\left(t-t_{3}\right)}+b_{2}(T) e^{-\delta(t-T)}+b_{3}(\bar{T}) e^{-\delta(t-\bar{T})} .
$$

Figure 3 shows the atmospheric pollution over time that results from the different extraction scenarios, under the assumption that $\alpha=0.25$. As $t$ approaches infinity, the atmospheric polluting stock of anthropogenic carbon converges to $V(t \rightarrow \infty)=625$. This is because a fraction $(1-\alpha)$ of the anthropogenic carbon stock depreciates from the atmosphere over time. Moreover, in the case of a capacity expansion (an increase in $\bar{q}_{3}$ ) and tax on the highcost exhaustible resource, the peak of accumulated pollution is clearly lower than in the base case, while for subsidization of the green energy and for a tax on the low-cost exhaustible resource, it is quite similar to the base case. Regarding the tax on $S_{2}$, this is because emissions are postponed ( $\bar{T}$ is very large) and therefore the time path of the pollution stock is flatter. Regarding the capacity expansion scenario, pollution is slightly higher in the beginning such that due to the constant decay rate, more carbon has already depreciated from the atmosphere when the peak of the atmospheric pollution stock is reached.

Based on the pollution paths, the welfare effects of the different policy measures are calculated and compared. Analogous to the previous section, if the damage function $C[V(t)]$ is linear, say $C[V(t)]=\theta V(t)$, and using the above notation together with equations (46) - 

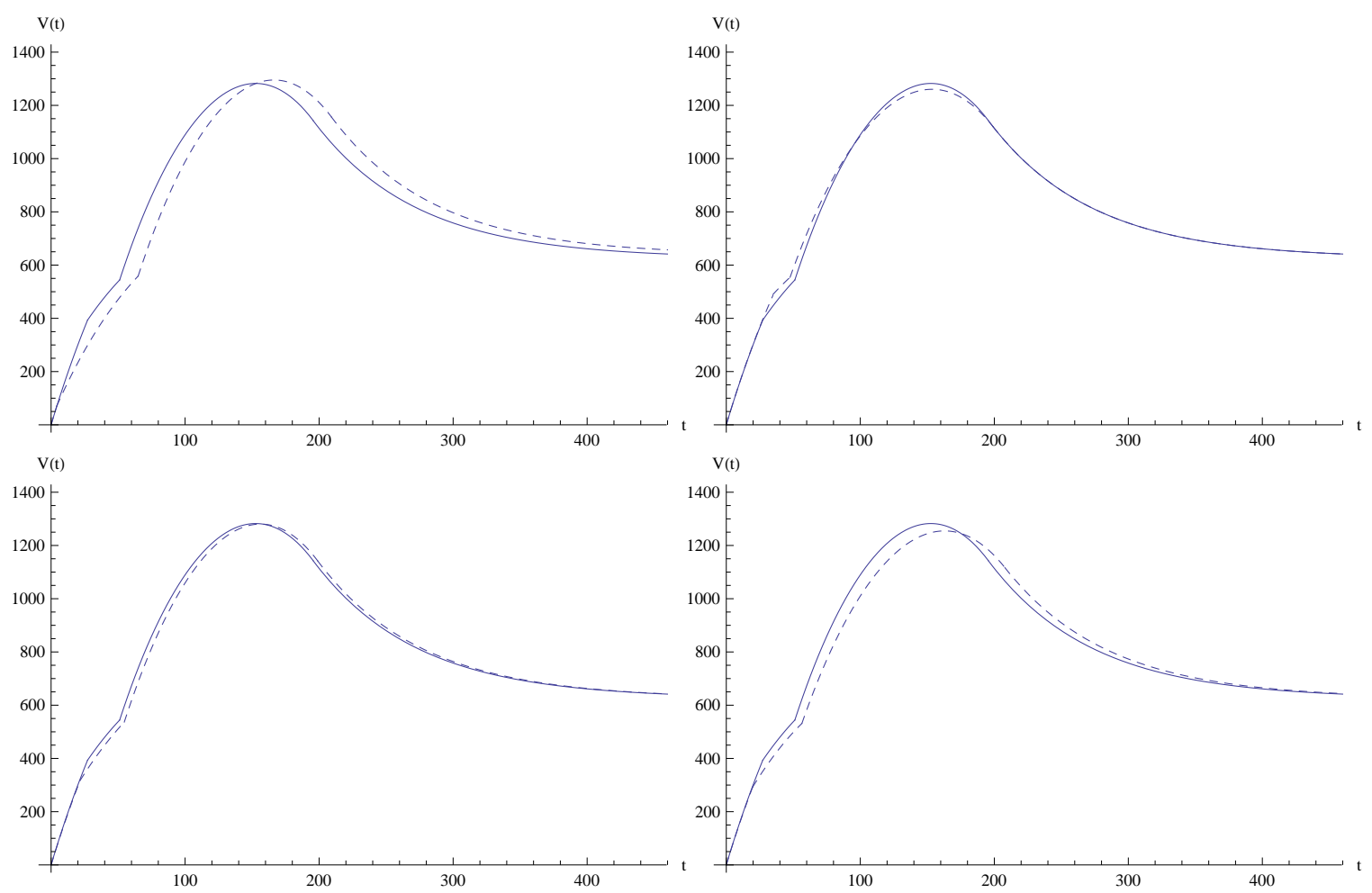

Figure 3: Accumulated pollution of policy scenarios compared with base scenario and positive decay

(49), the integral of the stream of discounted damages over all phases is

$$
\begin{aligned}
& D\left(t_{0}\right)=\int_{0}^{t_{3}} e^{-r t} \theta\left[a_{1}(t)+b_{1}(t)\right] d t+\int_{t_{3}}^{\infty} e^{-r t} \theta\left[a_{1}\left(t_{3}\right)+e^{-\delta\left(t-t_{3}\right)} b_{1}\left(t_{3}\right)\right] d t \\
& +\int_{t_{3}}^{T} e^{-r t} \theta\left[a_{2}(t)+b_{2}(t)\right] d t+\int_{T}^{\infty} e^{-r t} \theta\left[a_{2}(T)+e^{-\delta(t-T)} b_{2}(T)\right] d t \\
& +\int_{T}^{\bar{T}} e^{-r t} \theta\left[a_{3}(t)+b_{3}(t)\right] d t+\int_{\bar{T}}^{\infty} e^{-r t} \theta\left[a_{3}(\bar{T})+e^{-\delta(t-\bar{T})} b_{3}(\bar{T})\right] d t
\end{aligned}
$$

where the first line describes the stream of discounted damages of the first period emissions, the second line those of the second period emissions and the third line those of the third period emissions until infinity.

Inserting the values of the numerical analysis into equation (50) allows us to directly compare the welfare effects of the different policy scenarios with the business as usual case. Under the linear damage function, comparing the discounted damages of the period between 
0 and infinity for the different policy scenarios as previously gives

$$
D^{\operatorname{tax} 2}\left(t_{0}\right) \leq D^{\text {subsidy }}\left(t_{0}\right) \leq D^{\operatorname{tax} 1}\left(t_{0}\right) \leq D^{\text {base case }}\left(t_{0}\right) \leq D^{\text {capacity }}\left(t_{0}\right) .
$$

In contrast, with the convex damage function (45), we obtain a somewhat different ranking of the discounted stream of damages for the different policy scenarios:

$$
D^{\operatorname{tax} 2}\left(t_{0}\right) \leq D^{\operatorname{tax} 1}\left(t_{0}\right) \leq D^{\text {subsidy }}\left(t_{0}\right) \leq D^{\text {base case }}\left(t_{0}\right) \leq D^{\text {capacity }}\left(t_{0}\right) .
$$

As before, three of the four policy measures are welfare increasing compared to the laissezfaire situation. Again, only a capacity increase of the renewable backstop leads to higher damages compared to the base case. However, in the latter situation of positive decay rate and a convex damage function, the damage order changes compared to the scenario with a positive decay rate and a linear damage function, as well as compared to the other situations previously analyzed. Here, a tax on the high-cost exhaustible resource reduces damages the most compared to the base case, whereas subsidizing the green product is the third-most effective instrument. This might be because in the subsidy scenario, emissions are higher in the beginning, and therefore damages, due to the underlying convex damage function, are relatively higher than with the linear damage function.

The generally poor performance of the capacity increase scenario has been found, in the light of Gerlagh (2011)'s definition of a strong green paradox. A relaxation of the capacity constraint of the green substitute leads not only to an increase in the near-term emissions but also to an overall welfare loss for society and, therefore, a strong green paradox occurs. Such a capacity increase might result from technological progress (e.g., second-generation biofuels), but can also be induced by similar policy measures (e.g., when the government allows import of a biofuel previously banned from the market). This green paradox result is summarized in Proposition 8.

Proposition 8: Numerical simulations show that a capacity expansion of the green energy substitute leads to a strong green paradox since it reduces social welfare compared to the laissez-faire case. 


\section{Policy relevance}

The model presented in this paper exhibits a considerable degree of flexibility and is able to capture various current problems. To illustrate this broad applicability, this section provides evidence that supports this paper's approach, showing that it is highly relevant. In addition to the oil market application mentioned in Section 4, this sectionshows, by way of illustration, that the model can also be used to analyze the transformation of the electricity sector.

As already shown in Section 4, a natural application of our model is an oil market with conventional and unconventional oil as well as biofuels as the clean substitute. The cost structure and environmental impacts may be stylized as it is done in Section 4. The consideration of two rather than one "dirty" resource is supported by the recent emergence of unconventional carbon resources such as extra heavy oil, oil sands, and oil shale (Gordon, 2012). ${ }^{19}$ Extracting oil from unconventional sites is more costly as well as more energy intensive and, thus, unconventional oil has a different $\mathrm{CO}_{2}$ emission intensity and cost structure than conventional oil. The modeling framework applied here is well suitable for capturing this issue. Specifically, beside different technological problems, biofuel production raises sustainability and food security concerns in that there might not be enough suitable land available for biofuel production and, even if there were, using it for that purpose might seriously compromise food production. Thus, it seems to be the case that there is a constraint imposed on the share of green energy production. The share of biomass from global primary energy supply is currently about $15 \%$. This, however, is to a very large extent attributable to so-called "traditional biomass" - the use of firewood, charcoal as well as agricultural residues (IEA, 2012). The share of biofuels in global road transport, however, is merely $3 \%$ and several problems indicate that it is more than reasonable to assume that biomass is not a backstop technology that can be used without constraints. ${ }^{20}$ A core result of the theoretical as well as numerical analysis is the negative evaluation of the capacity expansion scenario. Therefore, the enormous biomass potential can be a considerable problem. In light of these findings, transport sector policies such as blending mandates must be analyzed carefully regarding possible green paradox effects.

\footnotetext{
${ }^{19}$ This might also be seen as an approximation of an increasing (instead of flat) marginal cost curve.

${ }^{20}$ Even though projections certainly indicate that there is a vast potential for biomass (for example, unused and surplus land, has the potential of about 550-1,500 EJ biomass production in 2050 (IEA, 2011)), the way to exploit this potential is nevertheless long and stony. To mention just a few of the challenges, crop yields need to increase considerably, and substantial parts of grassland need to be converted. In addition to that, IEA (2011) points to regulatory requirements and stresses the importance of ensuring that food security is not compromised (see also Sinn, 2012).
} 
The already mentioned electricity sector is another possible application of our model. There is a similar situation present as in the fuel market example: electricity is generated from both different "dirty" and exhaustible conventional resources as well as green ones simultaneously - despite the fact that renewable energy is considerably more expensive than electricity conventionally produced. Widely discussed topics like climate change, energy security or resource scarcity increase the attractiveness of using renewable energies such as, for example, wind or solar power rather than (or at least in addition to) coal or gas. In consequence, policy instruments such as feed-in-tariffs are in place in many countries. For example, Germany generates $20 \%$ of total electricity from renewable sources such as wind and solar and the European Union aims at reaching this share even at the European level. Clearly, there are limits to increasing this share. ${ }^{21}$ In other words, assuming that a backstop resource for electricity generation is unrestrictedly available would be problematic. The results of our model, however, indicate that, for example, feed-in-tariffs are not without problems (weak green paradox) but may have positive long-term effects. ${ }^{22}$

There are even more ways of interpreting our model. An example is nuclear energy - a "conventional", but carbon-free energy source, which is capacity-constrained by both technological as well as political restrictions. More generally, in contrast to the case where the renewable energy is clean, the case where the backstop technology is dirty, however, is also of interest (see, e.g., van der Ploeg and Withagen, 2012a). Regarding a dirty backstop, one might think of coal, which might be used to produce electricity, but also of fuels produced with coal-to-liquids technologies.

These reflections bear impressive witness to the broad applicability of this paper's model. It is fairly obvious that applications of this model make an important contribution to current energy policy debates. In a nutshell, the model applied in this paper can capture different situations that are currently present. At the same time, the results obtained in this paper clearly indicate that neglecting the important feature of capacity constraint backstop technologies can lead to wrong policy decisions.

\footnotetext{
${ }^{21}$ For example, substantial adjustments of the electricity transmission network are required. What is more, finding solutions for the related problems of intermittent renewable energies and the considerable lack of storage facilities is anything but easy. In addition to these technological challenges, there are also important regulatory ones. The requirement of backup power plants to guarantee network stability sparked the debate on an entire redesign of electricity market - see the discussion on so-called capacity markets (IEA, 2012). Since the present paper only focuses on the supply side production decisions of energy goods, a further consideration of those topics would be beyond the scope of this paper.

${ }^{22} \mathrm{~A}$ detailed analysis of possible green paradox effects in the electricity market requires a corresponding calibration of the numerical model.
} 


\section{Summary and conclusions}

This paper addresses the considerable difficulty of decarbonizing the economy and analyses the behavior of agents, especially regarding the supply side of energy production, to obtain a clearer understanding of how various policies may affect the energy markets. The model applied in this paper has two important features. First, it encompasses three different resources with different extraction costs. One of these resources is assumed to be "green" and capacity-constrained. ${ }^{23}$, as it has been demonstrated in the previous section. Second, the model allows resources with different extraction costs to be used simultaneously. These two features distinguish this paper from the majority of recent work on climate policies.

Based on the partial equilibrium model of Holland (2003), we analyzed the effects of different climate policies on an energy market characterized by several cheap but dirty fuels and a green but expensive and capacity-constrained substitute, with particular reference to the concrete fuel market. After an implicit determination of the endogenous variables, we analyzed the effects of four different policy scenarios on supply-side extraction and production behavior, as well as the resulting energy price path, using a comparative static approach. The analysis was complemented by a numerical section in which the model and its results were illustrated concretely. Additionally, an extensive welfare analysis was conducted using various specifications for the amount and development of anthropogenic carbon in the atmosphere as well as alternative specifications of the environmental damage function. We tested our comparative static results for three different types of green paradox: the weak green paradox of Gerlagh (2011), which involves a short-term increase of carbon emissions; the overall green paradox, which occurs when the overall extraction duration of all available fossil fuels is shortened; and the strong green paradox (Gerlagh, 2011), which arises when overall welfare decreases as a consequence of a policy measure. We found a weak green paradox for subsidization of the green energy, and both a weak and a strong green paradox for capacity enhancement.

The basic point of a green paradox can be simply summed up as "good intentions do not always breed good deeds" (Sinn 2008). Or, more specifically for our paper, a green paradox arises when a policy measure intended to slow down resource extraction so as to increase overall social welfare achieves the exact opposite effect. This basic effect can occur via various channels, including intertemporal, spatial, technological, or extraction order effects (for

\footnotetext{
${ }^{23}$ The "backstop" literature usually assumes that at a certain point in time, a backstop technology becomes available as well as competitive and that from then on all energy is generated from this "green" resource. Such an assumption fails to reflect the reality
} 
more details, see, e.g., van der Werf and Di Maria, 2011). Intertemporal effects were pointed out in Sinn (2008), referring earlier analysis of firm's extraction decisions in anticipation of future tax changes (Long and Sinn, 1985). ${ }^{2425}$ A technology-induced green paradox was pointed out in Strand (2007). For our analysis, the intertemporal as well as the extraction order effect are important. The intertemporal effect can be found both for subsidization and capacity enhancement of green energy goods. In either case, the policy measure decreases future resource rents and therefore increases the (short-term) extraction speed of fossil fuels. We find an extraction order effect by using Holland (2003) basic conditions for a cost reversal to occur. Moreover, as illustrated by our oil market example, a policy that delays production of the green substitute can also be seen as a green paradox in the extraction order sense, which is exactly what occurs in the capacity enhancement scenario.

Even though our green backstop was pared down to its most simple form and did not include, for example, the possibility of a gradual relaxation of the capacity constraint or any uncertainty about its success, we found unambiguously that the existence of a capacity constraint on the green substitute technology casts doubts on the welfare effects of some policy measures that intend to reduce carbon emissions (to transfer them into the future) or promote green energies. This is of significant consequence for policy advice. This feature differentiates our results from the general conclusions of the existing green paradox literature. For a policymaker who wants to support green energy to reduce anthropogenic carbon emissions, the welfare analysis implies that a tax on the high-cost exhaustible resource has the best welfare effects. A subsidy for the green energy seems also to be a useful instrument since it reduces the costs of production without crowding out the exhaustible resources. This is the case due to the existence of a capacity constraint even if it leads to a weak green paradox. We find that a reneweable energy sector subject to capacity constraint, a characteristic of green energy that we can actually observe, reduces at least to some extent the reliance on exhaustible resource and thereby helps policymakers to implement effective climate policies. However, if for example the production capacity of the green substitute becomes "too big", the results could turn around and produce welfare decreasing effects since then, the green

\footnotetext{
${ }^{24}$ Sinclair $(1992,1994)$ pointed out that carbon tax should start at a high level and fall over time, contrary to the usual policy prescription (Nordhaus, 2007). This is in the same spirit as Sinn (2008). Hwang and Mai (2004) showed a green paradox result in a spatial model.

${ }^{25}$ While the model of Hwang and Mai (2004) does not deal with open economies, by endogenizing the choice of a firm's location, it is pointing out to a root of the Green Paradox: policy makers quite often fail to take into account the full ability of firms or individuals to make spatial or intertemporal adjustments to their plans in response to policy measures. The literature on "carbon leakage" is based on the same insight. For example, the carbon-leakage model by Babiker (2005) assumes spatial competition among Cournot oligopolists, a feature that has been exploited in modeling firms' locational choice (Markusen and Venables, 1988, Markusen et al., 1993, 1994).
} 
technology is treated as a normal backstop by the resource owners, and anticipations of reduction in costs of this technology can induce rapid extractions of the exhaustible resources, as shown by Strand (2007) and Hoel (2008).

However, the results of the welfare analysis show that the underlying parameters of the model must be carefully considered when making recommendations to policymakers, since different choices of parameter values will result in different effects and trade-offs. For example, changing the time horizon or time preference rate might change the welfare order. ${ }^{26}$ To avoid the specific problems associated with finite time horizons, in the present model we chose an infinite horizon so as to capture all socially relevant effects. Another point worth emphasizing is that in the event of partial depreciation of the atmospheric stock of carbon (which is the real-world situation), the two parameters $\delta$ and $r$ work in the opposite direction when it comes to their policy implication: a higher discount rate $r$ may tend to imply policy action that postpones carbon extraction so as to push the damages far into the future, whereas a higher decay rate $\delta$ might even induce a shortening of the extraction period. ${ }^{27}$ Consequently, with $\delta>0$ and $r>0$, we have a trade-off between these two parameters. The longer we can postpone extraction, the lower tend to be the damages due to the positive social discount rate. On the other hand, the higher the current emissions, the higher the future absolute depreciation in the atmosphere. Moreover, the analyzed policy measures are comparable only under certain conditions because our energy market model is, by necessity, only partially reflective of reality and does not cover all possible social consequences or necessarily offer first-best policy options.

Another limitation of our model is that we modelled the cost structures as well as the capacity constraint in a very simple way. However, both simplifications are widely used in literature and accepted as approximations for more elaborated cost and capacity structures actually observed in energy markets. The two exhaustible resources with different cost structures can be understood as a single energy good which becomes more difficult to produce (both more costly as well as more carbon intensive) with increasing scarcity. Since we need two exhaustible energy goods to illustrate our oil market example, this is another reason for introducing two exhaustible resources instead of only one. Moreover, we abstained from introducing a more realistic capacity constraint of the renewable energy good since our simply constructed capacity constraint is sufficient to demonstrate the mechanisms and implications we are interested in. A more realitic formulation of capacity constraint may be is possible,

\footnotetext{
${ }^{26}$ One might argue, for example, that politicians have a relatively high time preference rate, or short time horizons.

${ }^{27}$ This is because $\delta$ is a constant rate of decay: the higher the emissions per period of time, the higher the absolute decay in the following periods and the faster it converges towards $C[\alpha V(t)]$.
} 
based on a convex cost structure. However, under a suitable specification, the results would not differ, only the calculations would be more complex.

Our approach should thus be viewed as a first step toward analyzing the complexity of energy markets comprised of a variety of energy goods with a special focus on capacityconstrained green backstops. To our knowledge, this very important aspect of energy markets is mostly ignored in the literature. One interesting possibility for future research would be to discover first-best energy policies in a general equilibrium model with capacity-constrained energy sources. It would be interesting to analyze the policy measures and resulting tradeoffs in a model that includes growth of the available green energy. Another interesting idea would be to derive socially optimal investments in green capacity technology with an endogenous capacity constraint. Moreover, a closer look at the green substitute is needed, which could be attained by analyzing, using a model with an exogenously increasing green capacity, the trade-offs in the extraction and production decisions of various energy suppliers. Further important topics that need more attention are strategic interactions as well as the impact of uncertainty on policy action.

\section{APPENDIX}

In this Appendix, we identify conditions for the parameter values such that $T$ is exactly equal to $t_{3}$, Phase 2 , collapsing to a single point. If $T=t_{3}$, then from time $t_{3}$, energy supply comes both from deposit 2 and from the clean energy sector (deposit 1 having been exhausted, we have identical starting-times of clean energy production and extraction from the high-cost deposit with $T=t_{3}$ ). As defined before, the time at which deposit 2 is exhausted is called $\bar{T}$. At $\bar{T}$ and from then on, the price of energy must equal $\bar{p} \equiv U^{\prime}\left(\bar{q}_{3}\right) \equiv \phi\left(\bar{q}_{3}\right)$. During the time interval $t \in\left[t_{3}, \bar{T}\right)$, the Hotelling rule must hold for deposit 2 :

$$
\left(p(t)-c_{2}\right) e^{-r t}=\left(p\left(t_{3}\right)-c_{2}\right) e^{-r t_{3}}=\left(p(\bar{T})-c_{2}\right) e^{-r \bar{T}} \equiv\left(\bar{p}-c_{2}\right) e^{-r \bar{T}}
$$

From this equation, the explicit price path between $t_{3}$ and $\bar{T}$ as well as the extraction duration can be determined. With $p\left(t_{3}\right)=c_{3}$, it follows that the length of time it takes for the price to rise from $c_{3}$ to $\bar{p}$ is

$$
x=\frac{1}{r} \ln \left[\frac{\bar{p}-c_{2}}{c_{3}-c_{2}}\right]
$$

where $x$ is defined as

$$
x \equiv \bar{T}-t_{3}
$$


Moreover, for all $t \in\left[t_{3}, \bar{T}\right)$, the price path is

$$
p(t)=c_{2}+\frac{\left(p\left(t_{3}\right)-c_{2}\right) e^{-r t_{3}}}{e^{-r t}}=c_{2}+\left(c_{3}-c_{2}\right) e^{r\left(t-t_{3}\right)} .
$$

From this, the total demand for energy over the time interval $\left[t_{3}, \bar{T}\right)$ can be determined as

$$
\int_{t_{3}}^{\bar{T}} D[p(t)] d t=\int_{t_{3}}^{\bar{T}} D\left[c_{2}+\left(c_{3}-c_{2}\right) e^{r\left(t-t_{3}\right)}\right] d t
$$

Then, we use $x \equiv \bar{T}-t_{3}$ and the substitution $\tau=t-t_{3}$ to obtain

$$
\int_{0}^{\bar{T}-t_{3}} D\left[c_{2}+\left(c_{3}-c_{2}\right) e^{r \tau}\right] d \tau \equiv \int_{0}^{x} D\left[c_{2}+\left(c_{3}-c_{2}\right) e^{r \tau}\right] d \tau
$$

Total demand must be met by total supply, which is the output of the clean energy sector and extractions from deposit 2 :

$$
\int_{0}^{x} D\left[c_{2}+\left(c_{3}-c_{2}\right) e^{r \tau}\right] d \tau=x \bar{q}_{3}+\int_{0}^{x} q_{2}(\tau) d \tau\left(\text { recall } \tau=t-t_{3}\right) .
$$

It follows that if $S_{2}$ is just equal to a threshold value $S_{2}^{\max }(\infty)$ defined by

$$
S_{2}^{\max }(\infty) \equiv \int_{0}^{x} D\left[c_{2}+\left(c_{3}-c_{2}\right) e^{r \tau}\right] d \tau-\frac{\bar{q}_{3}}{r} \ln \left[\frac{\bar{p}-c_{2}}{c_{3}-c_{2}}\right]
$$

then $t_{3}$ is indeed the time at which deposit 2 begins to be extracted (and sold at price $p\left(t_{3}\right)=c_{3}$ at that moment), and the time at which deposit 1 has just been exhausted.

Can we determine time $t_{3}$ in this case? Analogous to the above, since over the time interval $\left[0, t_{3}\right)$ deposit 1 is being exploited, the Hotelling rule applied to deposit 1 must hold with equality for all $t \leq t_{3}$ :

$$
\left(p(t)-c_{1}\right) e^{-r t}=p(0)-c_{1}=\left(c_{3}-c_{1}\right) e^{-r t_{3}}
$$

Rearranging gives us the price path between $t=0$ and $t=t_{3}$ and, under the consideration that total demand must be met by total supply, we obtain

$$
\int_{0}^{t_{3}} D\left[c_{1}+\left(c_{3}-c_{1}\right) e^{-r\left(t_{3}-t\right)}\right] d t=S_{1}
$$

This equation determines $t_{3}$ and hence $p(0)$ as functions of $S_{1}$ (given the assumption that $\left.S_{2}=S_{2}^{\max }(\infty)\right)$. We summarize the results for this razor's edge case as Proposition 1 . 
Proposition: (Razor's edge case) If the size of deposit 2 is equal to the threshold value $S_{2}^{\max }$ defined by

$$
S_{2}^{\max } \equiv \int_{0}^{x} D\left[c_{2}+\left(c_{3}-c_{2}\right) e^{r \tau}\right] d \tau-\frac{\bar{q}_{3}}{r} \ln \left[\frac{\bar{p}-c_{2}}{c_{3}-c_{2}}\right],
$$

where

$$
x \equiv \frac{1}{r} \ln \left[\frac{\bar{p}-c_{2}}{c_{3}-c_{2}}\right],
$$

then the equilibrium time path of extraction is continuous and consists of three phases:

Phase 1 (the time interval $\left[0, t_{3}\right)$ ): The whole market is supplied from deposit 1 only: $Q=q_{1}$. This deposit will be exhausted at time $t_{3}$, where $t_{3}$ is the solution of

$$
\int_{0}^{t_{3}} D\left[c_{1}+\left(c_{3}-c_{1}\right) e^{-r\left(t_{3}-t\right)}\right] d t=S_{1} .
$$

At time $t_{3}$, the price of energy is $p\left(t_{3}\right)=c_{3}$.

Phase 2 (the time interval $\left[t_{3}, \bar{T}\right)$ ): The whole market is supplied from both the high.cost deposit (deposit 2) and the clean energy sector: $Q=q_{2}+\bar{q}_{3}$ where $q_{2}(t)>0$ for all $t$ in $\left[t_{3}, \bar{T}\right)$. The length of this phase is equal to $x$. At time $\bar{T}$, the price of energy is $\bar{p}$, and deposit 2 is exhausted.

Phase 3: After time $\bar{T}$, the whole energy market is satisfied by the clean energy sector: $Q=\bar{q}_{3}$.

\section{References}

[1] Archer, D., 2005, Fate of fossil fuel $\mathrm{CO}_{2}$ in geologic time. Journal of Geophysical Research 110, C09S05, doi:10.1029/2004JC002624.

[2] Amigues, J.-P., Favard, P., Gaudet, G., Moreaux, M., 1998, On the optimal order of natural resource use when the capacity of the inexhaustible substitute is limited, Journal of Economic Theory 80 (1), 153-170.

[3] Babiker, M. H., 2005, Climate Change Policy, Market Structure, and Carbon Leakage, Journal of International Economics, 65(2): 421-445. 
[4] Chakravorty, U., M. Moreaux, and M. Tidball, 2008, Ordering the Extraction of Polluting Non-renewable Resources, American Economic Review 98(3), pp. 1128-44.

[5] Dasgupta, P., and Heal, G., 1974, The optimal depletion of exhaustible resources, Review of Economic Studies 41, Symposium on the economics of exhaustible resources, $3-28$.

[6] Farzin, Y. H., and Tahvonen, O., 1996, Global carbon cycle and the optimal time path of carbon tax, Oxford Economic Papers 48 (4).

[7] Gerlagh, R., 2011, Too much Oil, CESifo Economic Studies 57 (1), 79-102.

[8] Gordon, D., 2012, Understanding unconventional oil, The Carnegie Papers.

[9] Grafton, Q., Kompas, T., and Long, N. V., 2012, Substitution between biofuels and fossil fuels: Is there a Green Paradox?, Journal of Environmental Economics and Management 64 (3), 328-341.

[10] Herfindahl, O.C., 1967, Depletion and economic theory, in: Mason Gaffney (Ed.), Extractive Resources and Taxation: Proceedings, University of Wisconsin Press, Madison.

[11] Hoel, M., 2008, Bush meets Hotelling: Effects of improved renewable energy technology on greenhouse gas emissions, CESifo Working Paper No. 2492.

[12] Hoel, M., 2011, The supply side of $\mathrm{CO}_{2}$ with country heterogeneity, Scandinavian Journal of Economics 113 (4).

[13] Hoel, M., and Kverndokk, S., 1998, Depletion of fossil fuels and the impacts of global warming, Resource and Energy Economics 18 (2), 115-136.

[14] Holland, S., 2003, Extraction capacity and the optimal order of extraction, Journal of Environmental Economics and Management 45 (3), 569-588. 
[15] Houghton, J. T., Callander, B. A., and Varney, S. K., (Eds.), 1992, Climate Change: Supplementary Report to the IPCC Scientific Assessment (Report from Working Group I, Intergovernmental Panel on Climate Change). WMO, UNEP, IPCC. Cambridge: Cambridge University Press.

[16] Houghton, J. T., Jenkins, G. J., and Ephraums, J., (Eds.), 1990, Climate Change: IPCC Scientific Assessment (Report from Working Group I, Intergovernmental Panel on Climate Change). WMO, UNEP, IPCC. Cambridge: Cambridge University Press.

[17] Hwang, H, and C.C. Mai (2005), "The Effects of Pollution Taxes on Urban Areas with Endogenous Plant Location," Environmental \& Resource Economics 29: 57-65.

[18] IEA, 2011, Technology roadmap - Biofuels for transport, Paris.

[19] IEA, 2012, World Energy Outlook 2012, Paris.

[20] Kemp, M. C., and Long, N. V., 1980, On two folk theorems concerning the extractions of exhaustible resources, Econometrica 48 (3), 663-673.

[21] Long, N. V. and Sinn, H.-W., 1985, Surprise Price Shift, Tax Changes and the Supply Behaviour of Resource Extracting Firms, Australian Economic Papers, 24(45): 278-289.

[22] Markusen, J. and A. Venables (1988), "Trade Policy with Increasing Returns and Imperfect Competition: Contradictory Results from Competing Assumptions," Journal of International Economics 24: 299-316.

[23] Markusen, J., E. Morey, and N. Olewiler (1993), "Environmental Policy when Market Structure and Plant Location are Endogenous," Journal of Environmental Economics and Management 24: 299-316.

[24] Markusen, J., E. Morey, and N. Olewiler (1995), "Competition in Regional Environmental Policies when Plant Location are Endogenous," Journal of Public Economics 56: 55-77.

[25] Nordhaus, W.D. (2007), The Challenge of Global Warming: Economic Models and Environmental Policy, Yale University. 
[26] Sinclair, P.J.N., 1992, High Does Nothing and Rising is Worse: Carbon Taxes Should Keep Falling to Cut Harmful Emissions, Manchester School 60: 41-52.

[27] Sinclair, P.J.N., 1994, On the optimum trend of fossil fuel taxation, Oxford Economic Papers 46, 869-877.

[28] Sinn, H.-W., 2008, Public policies against global warming: a supply side approach, International Tax and Public Finance 15 (4), 360-394.

[29] Sinn, H.-W., 2012, The green paradox: A supply-side approach to global warming. Cambridge, Massachusetts.

[30] Strand, J. 2007, Technology Treaties and Fossil Fuels Extraction, The Energy Journal 28: 129-142.

[31] van der Ploeg, R., and Withagen, C., 2011, Growth, Renewables and the Optimal Carbon Tax, OxCarre Research Paper 55.

[32] van der Ploeg, R., and Withagen, C., 2012a, Too much coal, too little oil, Journal of Public Economics 96(1), 62-77.

[33] van der Ploeg, R., and Withagen, C., 2012b, Is there really a green paradox? , Journal of Environmental Economics and Management 64 (3), 342-363.

[34] van der Werf, E., and Di Maria, C., 2011, Unintended Detrimental Effects of Environmental Policy: The Green Paradox and Beyond, CESifo Working Paper Series No. 3466. 